\title{
RUSSIA'S NEW CONCEPT OF THE STATE MIGRATION POLICY UNTIL 2025: A REFORM TOWARDS EFFECTIVE POLICIES FOR INTERNATIONAL ECONOMIC MIGRANTS?
}

\author{
IVA MIHAYLOVA \\ iva.mihaylova@unisg.ch \\ Swiss Institute for International Economics \\ and Applied Economic Research, \\ University of St. Gallen
}

\begin{abstract}
Russia's new Concept of the State Migration Policy until 2025 (the CSMP) was approved on 13 June 2012. As the first comprehensive, nationwide document on migration policy in the modern history of Russia, it marks the beginning of a decisive reform of the country's migration policy by departing from the existing focus on temporary foreign workers. The emphasis of the CSMP is on coordination between new, modernized, and reformed migration policies to help achieve its central goals: sustaining the country's economic competitiveness, alleviating the negative effects of the country's demographic decline, combating the deficiencies of the country's domestic labor market, attracting and retaining talented foreign workers, and facilitating the country's modernization and innovative development. This article first presents the principal elements of Russia's migration policy in the post-Soviet period. It explains the reasons for the legacy of problems arising from this policy that have motivated migration reform in Russia. Second, it describes the scope, stages, and policy measures of the new CSMP, with emphasis on its major new aspect - the selective recruitment and facilitated settlement of international economic migrants. Third, it provides recommendations to policy-makers, based on the relevant experience of other migrant-receiving countries. These recommendations are derived from a theoretical model for the important but often overlooked notion of the effectiveness of migration policy. The article entirely relies on a comparative learning method. By answering the question of whether a decision variable may be regarded as supplyled, demand-driven, or both, the recommendations of this analysis are summarized in the following categories: (1) models for selective migration policies; (2) state programs for foreign graduates of local universities; (3) temporary-to-permanent residence programs; (4) migration diasporas and skill-selective migration programs; and (5) labor market tests. The article concludes with a discussion of two points: (1) data quality and availability, and (2) the appropriate research methods for measuring the effectiveness of migration policies for international economic migrants.
\end{abstract}


Keywords: Russia; state migration policy; reform; international economic migrant

How to cite: Mihaylova, Iva (2017), "Russia's New Concept of the State Migration Policy until 2025: A Reform towards Effective Policies for International Economic Migrants?," Geopolitics, History, and International Relations 9(1): 176-214.

Received 7 June 2016 • Received in revised form 23 September 2016

Accepted 24 September 2016 • Available online 20 October 2016

\section{Introduction}

Governments around the world increasingly perceive value-added immigration as a winning factor in their adaptation to the competitive and knowledgebased conditions of the global economy, as a pro-economic growth factor, and as a remedy to the challenges of their ageing societies. In their recent joint report, UN-DESA and the OECD have identified the ten countries with the highest total number of international migrants living within their borders. The Russian Federation ranks second after the United States, which is the largest destination for immigrants. ${ }^{1}$ Migrants are an answer to Russia's sharp depopulation trend in the post-Soviet period. However, this remedy comes at a growing price in the form of illegal, lower-skilled, and irregularly concentrated regional migration. ${ }^{2,3}$ Because of the scale of these post-USSR migration-related trends, in mid-2012 the Russian government approved a new strategic document - the Concept of the State Migration Policy of the Russian Federation until 2025 (the CSMP). Its novelty consists in its unified approach to the creation of a structured legal framework for a comprehensive migration policy that targets different migrant groups. The emphasis of the CSMP is on the coordination of new, modernized, and reformed migration policies that help achieve its central goals: to sustain the country's economic competitiveness, to alleviate the negative effects its demographic decline, to combat the deficiencies of its domestic labor market, to attract and retain talented foreign workers, and to facilitate its modernization and innovative development. Australia, Canada, and the United Kingdom, as traditional migrant destinations, have been implementing such an approach for decades. In contrast, Russia's CSMP is the first state initiative of its kind in the postSoviet period. Previously, the policy focus was on temporary migration ${ }^{4}$ and the voluntary resettlement of compatriots living abroad. ${ }^{5}$

Against this background, evaluation of the effectiveness of migration policies, the relation between state migration goals on paper and actual outcomes (Czaika and de Haas, 2013: 495), ${ }^{6}$ is an important issue that should be of high priority to policy-makers. Castles (2012: 870) ${ }^{7}$ maintains that learning from well- or ill-conceived migration policies provides the necessary basis for creation of conceptual framework for studying the dynamics of contemporary migration and an answer to the essential policy question of why 
certain policy approaches fail. The author observes further that "[w]hether one focuses on policy success or policy failure, the point is to realize that such outcomes are not coincidental, but systemic and potentially changeable" (Castles, 2012: 870). ${ }^{8}$ From international perspective, the value added of studying the effectiveness of migration policies consists in the maintenance of higher adaptability to and integration within the context of global migration governance of the implementing country. Domestically, the assessment of the effectiveness of migration policies is also a crucial variable for acceptance of the political regime especially in democracies in which the preferences of the median voter are decisive. However, although the assessment of the effectiveness of migration policies is important, there exists a controversy in its current debate due to its conceptual fuzziness (Czaika and de Haas, 2013) ${ }^{9}$, scarcity of quantitative empirical studies (Czaika and de Haas, 2011), ${ }^{10}$ and lack of necessary data (Lowell, 2005; Koslowski, 2014). ${ }^{11}$

The purpose of this paper is threefold. First, it aims to describe the principal elements of the new CSMP with emphasis on its major new aspect the selective recruitment and facilitated settlement of international economic migrants. ${ }^{12}$ This emphasis is chosen because, as the official data of the Federal State Statistics Service of the Russian Federation for the period 2000-2013 in Figure 6 shows, it is the positive net migration rate that has partially alleviated the depopulation in Russia and may realistically be expected to play the same role in the future (Figure 3 ). Only economic immigration (as a profit-motivated international movement of actors, to be differentiated from asylum-seekers, refugees, and compatriots returning to Russia) will be analysed. ${ }^{13,14}$

Secondly, the article focuses on the highly-relevant in the CSMP context notion of effectiveness of immigration policies because its last implementation phase in the period 2021-2025 is dedicated to the assessment of the effectiveness of its state programmes, ${ }^{15}$ or a sub-set of the designed on its initial stage state interventions. Hence, the CSMP does not specify explicitly whether all migration policies and measures will be assessed on the basis of their effectiveness. It neither provides a definition for this notion. Due to these facts, this article undertakes a systematic approach and seeks to provide an answer to the question of what experience of other countries with regard to the effectiveness of their migration policies for international economic migrants may be relevant for any state intervention that forms an integral part of Russia's CSMP. Thirdly, this article offers recommendation to policy-makers on the basis of the global experience for well- or ill-conceived migration policies for international economic migrants under analysis.

The rest of the article is structured as follows: section 2 discusses the legacy of the Russian migration policy that was in effect from the post-Soviet period onwards; section 3 provides an overview of the "Concept of the State Migration Policy of the Russian Federation until 2025" with emphasis on its 
state interventions for international economic migrants; section 4 discusses the international economic migration policy experience of other countries and formulates recommendations for Russia. These recommendations are summarized in section 5. Finally, conclusions are drawn in section 6.

\section{Legacy of the Russian Post-USSR Period Migration Policy}

The purpose of this section is to discuss the key features of Russia's migration policy in the post-USSR period, as well as the legacy of problems that it left behind that motivated the introduction of the CSMP.

After the dissolution of the Union of Soviet Socialist Republics (USSR) in 1991, the Russian state migration policy distinguished migrants by their place of origin. This approach was motivated by the willingness of the Russian government to give the citizens of the former Eurasian states the right to choose the post-USSR country in which they wished to live. In the period 1989-2002, total net migration was 5 million, of which 67\% were Russians, but it considerably and consistently decreased thereafter. ${ }^{16}$ In the period 2003-2007, only 0.3 million Russians contributed to population growth. ${ }^{17}$ Until 1 January 2015, as part of the state program for facilitating the voluntary resettlement into Russia of compatriots living abroad that was introduced with Decree No. 637 of 22 June 2006, a total of 0.254 million people (inclusive of family members) submitted a request to resettle in the country. ${ }^{18}$ The Russian President Mr Vladimir Putin has stated that, in order to curb the depopulation of Russia, an annual migration inflow of 0.3 million people must be secured, who should be, in the first place, compatriots living abroad, highly qualified specialists, and young people with good prospects. ${ }^{19}$ However, recent 2008-2014 statistical data in Figure 10 demonstrates that the average annual number of applications of compatriots as part of this state program totaled approximately 0.04 million, far less than the stated requirement.

In line with Russia's post-USSR migration regime focused on origin as a selection criterion, nationals of the Commonwealth of Independent States ${ }^{20}$ benefited until 31 December 2014 from visa-free entry into the country and the right to a 90-day stay after their arrival date. Within this period, they could obtain a work permit by themselves, saving their employers the administrative work involved in this, and, other conditions being equal, increase their employability.

In contrast, for the same time period until 31 December 2014, employers wanting to hire foreign workers from countries for which a visa was required were subject to higher administrative formalities. Each year they had to submit to the relevant state authorities the number of such foreign workers they would need, which entailed careful planning. In addition, employers 
needed to obtain permission for the recruitment and work engagement of such migrants, and an invitation allowing each individual foreign worker to enter Russia. It was also the employer's duty to present the state authorities with housing and medical guarantees, and to inform the local section of the Federal Migration Service about all major events related to the employment history of the foreign worker arriving under a visa-requiring regime. The recruitment costs for employers were also considerable. For example, the approved on 21 July 2014 and entered into force on 1 January 2015 state fees for each single foreign worker were as follows: for the invitation for entrance into Russia - 800 RUB (0.13 times the 2015 minimum salary), for the issuance of a permit for recruitment and work engagement - 10,000 RUB (1.68 times the 2015 minimum salary), and for the issuance of a work permit $-3,500$ RUB (0.59 times the 2015 minimal salary). ${ }^{21}$ Permits for the recruitment and work engagement of foreign workers from visa-requiring countries and, in the majority of cases, their work permits, have to be renewed on an annual basis.

Since the beginning of this century, the structure of the net international economic migration of Russia has demonstrated some pronounced tendencies. First, regional CIS migration became by far the most common (93\% of the 2013 total migration balance, Figure 4). Second, concentrations of single ethnicity communities of immigrants from Central Asia have formed (Figure 5 ). In the net balance of migrants, men of working age predominate (Figure 7). Secondary general education is the most frequent level of qualification of CIS migrants (Table 1). Only $12.77 \%$ of the CIS immigrants and $14.40 \%$ of the immigrants from the rest of the world have a degree of higher education. In contrast, according to the National Population Census $2010,{ }^{22}$ the percentage of Russian citizens with higher education is considerably higher $(27.5 \%)$. Approximately half of the immigrants reside up to one year in Russia (Figure 9). Net migration has considerably surpassed the natural growth of the population since the 2000s (Figure 6). Illegal migrants working in the informal sector substantially outnumber the officially allocated quota (Figure 8). According to data of the Federal Migration Service, 5 million foreign nationals work illegally, according to the Ministry of Health of the Russian Federation - 8 million, while according to the Fund "Migration 21 Century" - approximately 10 million, or $12-13 \%$ of the whole working population of the country. ${ }^{23}$

Crimes by foreigners in Russia have displayed an upward trend in the post-USSR period. ${ }^{24}$ Social tension, xenophobia, and nationalism grew in parallel to the migration surge, illegal employment, and delinquency. According to the results of a social survey, the percentage of supporters of the slogan "Russia for the Russians" has climbed from 43\% in 1998 to 59\% in $2011 .^{25}$ The proportion of participants in the survey who indicated that the reasons for the rise in nationalism were "provocative actions, behavior of the 
national minorities" has increased from $25 \%$ in 2002 to $44 \%$ in 2011 . $^{26}$ Furthermore, a survey conducted at the end of 2011 explored attitudes towards the slogan "Enough feeding the Caucasus!" The results show that $28 \%$ of those questioned answered that they definitely supported the slogan, while $34 \%$ supported it to some degree. ${ }^{27}$

In response to these social and economic trends, the Russian government reformed the rules under which migrants may remain in the country and work. Starting from 2007, with the aim of bringing under control the considerable inflow of foreign nationals arriving mainly from visa-free countries, it introduced annual work permits and quotas for work permits. ${ }^{28}$ Figure 8 represents their trend towards a sharp decrease in their eight years of existence, a period that ended on 31 December 2014. As shown graphically for 2009-2010 by Vlasova (2012), while the number in the legally employed migrant labor force has fallen, the values of international money transfers made by migrants have increased, a fact the author attributes to rising illegal employment of migrants. Vlasova (2012) maintains that the low quota values and the imperfections of the legal system are among the principal reasons for the growth in illegal migrant employment. It should be noted that the arguments of the author are based on a correlation analysis that does not imply causation. Therefore, the question of whether migration quotas were ineffective, whether their effect was masked by other factors, or whether there were substitution effects present, as discussed by Czaika and De Haas (2013), ${ }^{29}$ is a topic for further research.

With effect from 1 January $2015,{ }^{30}$ the Russian government amended its policy concerning migrants from visa-free countries. It abolished the annual issuance of work permits and quotas for work permits, and replaced work permits by patents. A patent is defined ${ }^{31}$ as "a document confirming [...] the right of a foreign citizen [...] to temporary employment in the territory of the Russian Federation." Thus, a migration-related patent in Russia is a labor authorization document, and the word is not used with its common definition of a set of exclusive rights granted to an assignee under certain conditions. With this recent legal amendment, the Russian government has expanded the existing legal application of patents. Previously, patents authorized the employment of migrants as physical persons on labor or civil contracts only for the rendering of services and the production of goods for personal and household needs (for example, cooking and cleaning). Following this new legal amendment, they can be used for business activities, and their purchase is an obligatory prerequisite for the employment of the majority of foreign workers, if they arrive from visa-free (CIS) countries.

According to the Federal Migration Service, migrants in approximately half of the various migrant categories have little or no command of the Russian language and cannot communicate without the assistance of a translator; this is particularly true for young people from the countries of Central 
Asia that were founded after the dissolution of the USSR. ${ }^{32}$ One reason for this outcome is the lack of adaptation and integration measures in the pre-CSMP period, except for the 2006-approved state program for the support of compatriots living abroad who wish to resettle in Russia. Consequently, this poorly-integrated risk group of migrants suffers most frequently from discrimination and unlawful activities. ${ }^{33}$

In an ILO (2005) study on illegal migration, $74 \%$ of those interviewed indicated that they received their salaries without being registered in the employers accounting system and without the payment of taxes and accruals, while $20 \%$ confirmed that they lacked a written contract with their employer and described their work conditions as difficult. ${ }^{34}$ The study summarizes the most frequent forms of worker exploitation as coercion to work overtime (62\%), long delays in payments due from employers (39\%), coercion to perform tasks for which the employee has not given her/his consent (38\%), and unpaid work $(24 \%){ }^{35}$

In order to increase migrants' integration, in 2012 the Russian government introduced a requirement for foreigners applying for the issuance or renewal of a work permit for housing, communal, retail, or consumer services to present a state examination certificate proving their knowledge of the Russian language. ${ }^{36}$ These requirements for migrants were extended in $2014 .{ }^{37}$ The broad group consisting of foreign citizens who apply for a work permit, a patent, or a residence permit (with the exception of highly-qualified migrants) must certify their knowledge of Russian history and legislation, and demonstrate a predetermined level of command of the Russian language. The vast majority of work immigrants fall within the scope of this new piece of legislation because of the extended use of patents as of 1 January 2015.

To summarize, the problems that accumulated in the post-USSR period, such as illegal, lower-skilled, non-diversified CIS migration and social tension, motivated the introduction of the new Concept of the State Migration Policy of the Russian Federation until 2025, which will be presented, with a focus on international economic migrants, in the next section.

\section{The New Concept of the State Migration Policy of the Russian Federation until 2025}

Russia's new Concept of the State Migration Policy until $2025^{38}$ was approved on 13 June 2012. As the first comprehensive, nationwide document on migration policy in the modern history of Russia, it marks the beginning of a decisive reform in the country's migration policy with its departure from the previous focus on temporary foreign workers. ${ }^{39}$ The emphasis of the CSMP is on the coordination of new, modernized, and reformed migration policies that help achieve its central goals: to sustain the country's economic compet- 
itiveness, to alleviate the negative effects its demographic decline, to combat the deficiencies of its domestic labor market, to attract and retain talented foreign workers, and to facilitate its modernization and innovative development.

The CSMP policy trajectories ${ }^{40}$ are to be implemented as part of international cooperation and national migration policies. This article focuses entirely on the latter. At the national level, the main migration policy areas on which the CSMP concentrates are internal (domestic) and international migration. The CSMP targets citizens of the Russian Federation living in the country, compatriots living abroad who wish to relocate, relatives of independent immigrants, as well as educational, forced, and illegal migration. Thus, the focus is on three main migrant groups: humanitarian migrants (refugees), families of immigrants, as well as internal and international economic immigration, the last of these being the focus of this paper. Furthermore, the emphasis of this article is on the selective recruitment and facilitated settlement of this particular group of migrants, thus keeping a close link to the economic motivation of value-added migration, and, therefore, disregarding other CSMP policies related to social orientation, such as anti-discrimination, integration, adaptation, and language learning policies.

The CSMP is a strategic framework document in the form of a road-map. It was not intended to lay a detailed legislative foundation for all migration state interventions to be undertaken by the government before 2025. Additional implementation legal acts are to accomplish this goal. The CSMP is to be applied in three stages. During the first stage (2012-2015), ${ }^{41}$ legislation that ensures the fulfillment of its goals and main policy trajectories is to be developed and approved. State programs are also to be worked out. These programs are to be approved, monitored, and analyzed during the CSMP's second stage (2016-2020). ${ }^{42}$ The official CSMP text only states explicitly that the last phase of its implementation (2021-2025) is to be dedicated to the assessment of the effectiveness of the state programs designed in stage one, which constitute a sub-set of the planned to be introduced state interventions. Hence, the CSMP does not specify whether all migration policies and measures will be assessed on the basis of their effectiveness. It neither provides a definition for this notion. Due to this legal gap, the applied strategy in this article is to adhere to the definition of Czaika and de Haas (2013) ${ }^{43}$ for comparison of outcomes with goals that were declared on paper. In addition, CSMP's third stage is to include fine-tuning of strategic reference points, priorities, and policy trajectories concerning its implementation, as well as amendments to the respective state programs.

Similarly to other traditional migrant-receiving nations such as Australia, Canada, the UK and the United States, and a major novelty in the CSMP is the introduction of selective recruitment and facilitated settlement of migrants who are likely to have a positive net fiscal impact on the local economy, as 
well as to enhance its competitiveness. The rest of this section addresses the first purpose of the article by concentrating on the content of these CSMP measures as part of three policy trajectories: ${ }^{44}$

\section{1) Differentiated mechanisms targeting foreign workers}

As part of this policy trajectory will be elaborated effective labor market tests for determining the need for migrant labor, depending on the perspectives for development of the economy and the national labor market. Mechanisms for the recruitment of foreign workers for positions for which it is impossible to find Russian candidates are to be developed. ${ }^{45}$ Programs for the recruitment of (highly-)skilled foreign nationals, especially young people, to work in areas with high demand or with labor shortages in the local market, are to be implemented. Foreign workers who are in demand are to be encouraged by state mechanisms to sign long-term contracts. A simplification of the administrative rules, and the removal of restrictions concerning the arrival, employment, and study activities of members of the families of long-term employed foreign workers, is to be introduced. Migration formalities concerning the arrival, stay, and departure of individuals involved in entrepreneurship and business activities are to be simplified. A short-term program for seasonal workers is to be developed. Fine-tuning of the existing mechanism for the quota- and patent-based employment of foreign nationals is a further measure.

\section{2) Knowledge-based economy through educational and academic immi- gration and mobility}

The first policy trajectory formulates broad mechanisms that may be expected to affect any foreign worker whose competences and abilities help to reduce the imperfections in the local labor market and to enhance economic growth. The second one demonstrates an awareness of the role of knowledge and technology for the promotion of innovation-based economic development. In this regard, foreign graduates from Russian educational organizations are potentially highly-skilled workers who are likely to have strong language skills and to be a valuable source of positive financial and intellectual contributions to the local economy. Therefore, the CSMP declares that the number of foreign students at higher and secondary vocational educational institutions is to be increased. This state target is to be met predominantly by nationals of the Commonwealth of Independent States. Foreign students are to be granted the right to work during their studies on an equal basis with Russian students ${ }^{46}$ and the right to work in their field of specialization immediately after their graduation from a higher or secondary vocational educational institution in Russia. A further state measure is the implementation of a holiday employment program for students. 
Another group of stimulus measures enhances the mobility of highlyskilled migrant workers in education who perform teaching, research, and analytical work at educational institutions and scientific organizations. Their long-term recruitment is an explicit state goal. The state procedures for obtaining permanent residence for them and members of their families are to be simplified. The restrictions on the employment and education of the latter are to be removed as well.

\section{3) Preferential treatment for granting permanent residence status and citizenship to high-performing foreign nationals}

Qualified and other in-demand workers are to receive state support for obtaining permanent residence status. Foreign graduates from Russian educational institutions with qualifications in areas with high labor demand can take advantage of a preferential procedure for obtaining permanent residency. This group of migrants, together with foreign entrepreneurs, investors, qualified specialists, and members of the families of such migrants, will benefit from a simplified procedure to obtain Russian citizenship. The migration of foreign nationals for the purpose of family reunification is also to be facilitated. In addition, a selective points-based system for obtaining permanent residence is to be introduced.

This section has presented the principal elements of the CSMP concerning international economic migrants. The selective recruitment and facilitated settlement of foreign workers who will have a positive net fiscal, innovative, and economic impact has emerged as a principal consideration. The emphasis in the next section is on the relevant experience of migrant-receiving countries concerning international economic migrants. Recommendations for the future fine-tuning of the CSMP are derived on their basis.

\section{The Effectiveness of Migration Policy in the Experience of Countries Receiving Economic Migrants}

This section analyses the notions of "immigration policy" and "effectiveness" as formulated by Czaika and de Haas (2013) ${ }^{47}$ These authors define the first concept as "laws, regulations, and measures national states design and implement with the (implicitly or explicitly) stated objective of altering the volume, origin, and internal composition of immigration flows" (Czaika and de Haas, 2013: 503). Building on the argument that an immigration policy can be classified as such if documented, the authors define its effectiveness as the relationship between the written objectives of a policy and its subjectively assessed desired outcomes. Thus, "a policy's limited effect is not automatically 'policy failure' but only an 'inefficient' policy, implying that 
policy outcomes may not justify the amount of resources invested in producing these outcomes" ${ }^{\text {"8 }}$ (Czaika and de Haas, 2013: 497).

Different migration policies can target the same migrant groups. For example, a points-based system may target several tiers of immigrants with different levels of skills and qualifications. At the same time, some of these migrant groups may be eligible under other state migration programs. Hence, an overlap of "beneficiaries" may exist. Because of this fact, this section, as part of the second research goal of this article, does not explore the experience of other immigrant-receiving countries separately for each single economic migrant group within the three CSMP policy trajectories that have been presented. The implemented strategy has been to analyze and summarize the global experience by answering the question of whether a decision variable may be regarded as supply-led, demand-driven, or both (hybrid cases).

A question arises as to which countries have migration experiences that may be relevant for Russia and the goals of its new migration concept to sustain the states economic competitiveness, to alleviate the negative effects of the country's demographic decline, to combat the deficiencies of the domestic labor market, and to facilitate its modernization and innovative development. In this regard, the country choice for this study has been guided by several criteria. As a first priority references and recommendations have been made with regard to Australia, Canada, and the United Kingdom. This decision is motivated by the fact that these three countries, in a similar way to Russia, assign a high priority to coherent value-added migration policies in order to enhance their global competitiveness. ${ }^{49}$ In addition, Australia and Canada, unlike the United Kingdom but similarly to Russia, have as a state policy goal the recruitment of lower-skilled migrants. ${ }^{50}$ As a second priority, reference has been made to relevant empirical studies with panel data from high- and middle-income countries because they are likely to have experience of how to use foreign workers successfully as a complement to domestic employees. The emphasis of Russia's CSMP is on coherence and interconnectedness to other national goals. Therefore, appropriate policies of countries such as the United States, which do not explicitly ${ }^{51}$ have such a focus, are analyzed but given lower priority. Since the present topic is practice-oriented, the lowest priority has been given to relevant theoretic models. Finally, migration policies of countries of the Commonwealth of Independent States are not considered because, although they have experienced to a greater or lesser extent the influence of similar post-USSR demographic, economic, and social factors, their migration policies do not have comparable magnitudes and comprehensive objectives when compared to the new migration concept of Russia, the world's second largest receiver of immigrants. ${ }^{52}$

This study relies entirely on a comparative learning method. It does not combine this method with quantitative methods, implemented, for example, within the context of the relevant synthetic control for such research ques- 
tions ${ }^{53}$ because, although the objectives of Russia's new migration concept indicate that the experience of countries like Australia, Canada, and the United Kingdom may be a useful reference point, their combination as comparison units (synthetic controls) cannot adequately reflect Russia's characteristics as a unit of policy interest.

\subsection{Models for selective migration policies}

The migration literature usually highlights two pure models for the selection of economic migrants: supply-led and demand-driven. In reality, different features of these models are combined and implemented as new hybrid models ${ }^{54}$ in order to select foreign migrants with a particular profile. However, empirical evidence on the outcomes of the different models is scarce. The purpose of this section is to discuss the drawbacks of the supply-led and demand-driven models, on the basis of the few existing empirical works, as well as to introduce the main hybrid models for the selection of economic migrants. Next, sub-sections 4.1.1, 4.1.2, and 4.1.3 discuss the potential for the application of these hybrid models in Russia's CSMP context, and formulate recommendations.

The supply-led model is based on written rules (such as points-based requirements concerning migrants age, education, and language skills), which make it transparent. Its main drawback consists in the fact that, since the predefined written rules do not reflect the labor demand side of the local market, it may attract foreign workers who in theory comply with the rules but subsequently cannot find a job. ${ }^{55}$ Doomernik et al. (2009) cite Canada as an example of a country that initially implemented a detailed, points-based system that led to the ineffectiveness described. The demand-driven model suffers from the drawback that employers can manipulate the migration system. Hence foreign workers who are dependent on their employer become vulnerable. ${ }^{56}$

Papademetriou and Sumption (2011) ${ }^{57}$ admit that both models suffer from imperfections and suggest as a solution the implementation of a hybrid system as follows: (1) the concurrent use of an employer-led and a points-based system model for different migrant entrance routes; (2) the simultaneous use of an employer-led and a points-based system model for different migrant entrance routes; (3) the allocation of points within a points-based system for a job offer and the prioritization of the recruitment of foreign workers with pre-arranged employment; (4) a focus on foreign graduates of local universities as a source of workers who are likely to be highly-skilled; and (5) temporary-to-permanent programs with decision variables based on the foreign workers track record, and employer-led selection. Sub-sections 4.1.1, 4.1.2, and 4.1.3 discuss the potential for the application of these hybrid models in Russia's CSMP context, and formulate recommendations. 


\subsubsection{Hybrid models with supply-led and/or demand-driven elements}

The concurrent (Australia and Canada) ${ }^{58}$ and simultaneous (Singapore and the United Kingdom) ${ }^{59}$ use of employer-led and points-based systems involve skill and qualification criteria. They are used for fine-tuning foreign workers profiles. A prerequisite for such a policy is that the stock of migrants is sufficient, which is the case in traditional migrant-receiving countries. Therefore, a consideration of the strengths, weaknesses, opportunities, and threats related to its introduction is recommended after Russia's global migration attractiveness for (highly-)skilled migrants has been raised. ${ }^{60}$

The CSMP contains as an explicit goal a points system to be applied with respect to foreign nationals wishing to obtain a permit for permanent residence and not as a mechanism for different migrant entrance routes in the way that is discussed by Papademetriou and Sumption (2011). Table 2 contains the parameters of the second draft, dated 8 September 2015, of the points-based system for obtaining a permit for permanent residence in Russia. Compared to its first draft, ${ }^{61}$ a major change consists in the fact that the requirements for a minimal level of proficiency in the Russian language have been dropped. Language proficiency is scientifically proven to enhance the employability and integration of foreign workers in migrant-receiving countries ${ }^{62}$ and is a standard component in the points-based systems of traditional migrant destinations such as Australia, Canada, and the United Kingdom. Therefore, the inclusion of the possibility of allocating points for various levels of proficiency in the Russian language in the points-based parameters for obtaining permanent residence is recommended.

Another major amendment in the second draft of the Russian points-based model for obtaining permanent residence is the introduction of two new separate entrepreneurship categories - foreign investors in Russian entities and sole traders - with both groups rendering at least a certain minimum of state-requested financial contributions to the state budget. This approach most closely corresponds to the practice of various countries (the USA, the Netherlands, France, and Australia) that request a certain minimal investment in local businesses as a qualifying option for obtaining a visa or a residence permit. ${ }^{63}$ Compared to the other categories in Table 2, they allocate the biggest share of $77 \%$, respectively $62 \%$ of the minimally required 65 points for obtaining permanent residence. Thus, a clear signal is made that increasing the investment attractiveness of Russia is a major state priority. The combination with desirable age ${ }^{64}$ for both entrepreneurship categories, and even with primary education in the case of sole traders, renders the minimum necessary points for obtaining permanent residence. At the same time, foreign workers, who get the maximum 20 points via the age criterion, with secondary general education ${ }^{65}$ need at least 5 years' work experience in Russia and abroad in order to obtain the minimum number of points, according to the second draft 
of the Russian points-based model. Graduates from (non-)Russian universities who are likely to become highly-skilled employees, a common prerequisite for which is higher education, who score the maximum 20 points via the age criterion and 30 points for higher education, need another 15 points for work experience in Russia or abroad, which corresponds to 5 years, in order to obtain permanent residence.

The examples demonstrate that the second draft of the Russian pointsbased model overemphasizes the fiscal contributions of entrepreneurs, in that they can obtain permanent residence under conditions that they can instantly fulfill, while educated but less experienced immigrants and frequently those who are less well-educated in Russia would normally need more time in order to meet the minimum requirements. This imbalance, however, could be partially alleviated if Russian language skills, which were given up to 10 points in the document's first draft, were reintroduced as a selection criterion. Foreign graduates of Russian universities, an explicit CSMP target, are likely to be fluent in the Russian language. In addition, the vast majority of economic migrants are obliged from 1 January 2015 to demonstrate a certain level of proficiency in the Russian language in order to work in the country. Hence, if Russian language skills are reintroduced as a selection criterion in the Russian points-based model for obtaining permanent residence, they will give credit for skills that are likely to grow and have been proved to enhance integration and employability.

Sumption and Hooper (2014) ${ }^{66}$ analyze the global experience of investor immigration programs. They reach the conclusion that "policymakers have often found the results disappointing" (Sumption and Hooper, 2014: 1). Their list of the main challenges that investor immigration programs face includes the need for (increased) selectivity in host countries and the generation of higher economic benefits while restraining the size of the programs and keeping them free of scandal. This last point is of particular importance for maintaining the reputation of the CSMP. It is vulnerable because of its fast and uncomplicated pathway for international investors to permanent residence. Therefore, the implementation of careful applicant screening is recommended.

The third hybrid model discussed by Papademetriou and Sumption (2011), the allocation of points within a points-based system for a job offer, and the prioritization of recruitment for pre-arranged employment, is very closely related to the previous two hybrid models, and therefore is discussed within the same sub-section. It has been successfully applied in Canada in the context of a migrant entrance route. Russia could consider its application in two cases. First, it could be used in the future when the prerequisites for the application of the concurrent or simultaneous use of employer-led and pointsbased systems for different entrance routes are fulfilled. Second, it could be adapted to the existing Russian legislation, discussed in Section 2, concerning the entrance into the country of economic immigrants from visa-free 
and visa-requiring countries. Making economic immigration applications eligible for expedited processing if they have experience working in highdemand professions or have pre-arranged employment (or a job offer) is recommended.

\subsubsection{Focus on foreign graduates of local universities}

According to the CSMP, an increased awareness of the potential for foreign graduates of Russian universities to be a source of skilled labor is a key new priority for targeted state interventions. In line with this state goal, Federal Law No. 203-FZ of 23 July 2013 granted foreign students the right to work in Russia during their studies on the basis of a visa. Other conditions being equal, this state initiative is likely to increase Russia's attractiveness as a destination for international students. Concerning the design of state policies that give temporary access for skilled foreign workers to the labor market in the resident country, it may be of interest to consult the study of Matloff (2013). ${ }^{67}$ It discusses the effectiveness of the US temporary visa-based program for migrants, $\mathrm{H}-1 \mathrm{~B}$, in attracting foreign graduates from US universities with more talent than local graduates in the same area of studies. Matloff (2013) finds no evidence that foreign graduates have greater talent than US graduates on a number of measures. The author argues that programs like the H-1B visa program, because of their legal deficiencies, are used for hiring cheap, compliant labor. He indicates that a main legal loophole is the requirement for employers under the $\mathrm{H}-1 \mathrm{~B}$ scheme to pay the average wage in a given occupation, according to the region and years of experience, which does not reflect the true market value of the required skills and qualifications. In effect, US citizens as job applicants are disadvantaged. ${ }^{68}$ A similar view, that the H-1B scheme is used to employ foreign graduates in the IT sector at low rates of pay, which creates a disincentive for local graduates, is expressed in Salzman et al. (2013). ${ }^{69}$ The US H-1B scheme is relevant for Russia in that it demonstrates the outcomes that might be obtained if variants of the labor market tests discussed in Section 4.3 are not considered.

In addition, consideration of the introduction of policy measures that enhance foreign graduates' study-to-work adaptability, and the coordination of this transition process among employers and state institutions, is recommended. A survey ${ }^{70}$ conducted by the Research Unit of The Expert Council of German Foundations on Integration and Migration, focused on Canada, Germany, the Netherlands, and Sweden, indicates the major obstacles faced by international students, such as lack of adequate career support services, reluctance of employers to recruit them because of cost considerations and insufficient information, lack of work experience and professional and personal networks in the receiving country, as well as insufficient skills in the languages relevant to the job market in the migrant-receiving country as a 
consequence of the increasing number of programs being taught in English language.

\subsubsection{Temporary-to-permanent programs}

Ruhs $(2011)^{71}$ has conducted an empirical analysis of the labor immigration programs for low-, medium-, and highly-skilled migrants in 46 high- and middle-income countries. The author has reached the conclusion that the vast majority of labor immigration programs are temporary, while all existing permanent immigration programs target highly-qualified immigrants. Ruhs (2011) also find out that, as a rule, permanent residence is not granted automatically on arrival, but only after the successful transfer from a temporary status immigration program, and more skilled migrant workers are subject to fewer admission restrictions. This approach is referred to as a two-step process to admit permanent migrants. ${ }^{72}$ Marshall $(2011)^{73}$ justifies this approach on the grounds of its flexibility. By adducing Australia as an example, the author argues that during the first stage, temporary visas enable employers to recruit foreign workers quickly for growing industries, and offset the emigration costs of (highly-)qualified workers by offering them permanent residence at the second stage. In conclusion, the introduction of a two-step procedure with transparent transition pathways is recommended in Russia. The adaptability of temporary (highly-)skilled foreign workers and international graduates should be properly assessed during the first stage, and permanent residence with more rights should be offered during the second stage in order to discourage their emigration.

Migration measures for low-skilled foreign workers as a category of frequently temporary immigrants seem to be a lower priority for governments and frequently in the category "lessons learnt." Various studies demonstrate governments' and the general public's preference for high- over low-skilled immigrants $^{74}$ and "advanced liberal democracies' almost universal negative experience with temporary foreign worker programs" (Marshall, 2011: 26). ${ }^{75}$ Marshall (2011) summarizes the problems that have emerged in Canada as part of these programs: illegal migration due to diaspora effects, difficulties in protecting foreign workers rights due to lack of representation, dependence on their employer, and lack of paths for obtaining permanent residency that subsequently lead to permanently lower social status. Since vulnerability emerges as a principal problem, consideration of the introduction of a variant of the UK practice involving employer licensing is recommended. ${ }^{76}$ This practice is applied in the UK under its employer-led Tier 2 recruitment of foreign workers, and is based on employers' ratings for compliance with their obligations. As a sanction for non-compliance, an employer's license can be downgraded or revoked, thus depriving him/her of the possibility of recruiting 
foreign workers. This measure can be additionally reinforced by monitoring and carrying out random workplace visits.

Russia is the world's largest country by area, and it has significant regional disparities in its economic and demographic trends. One legacy of the Soviet planned economy is the high number of monotowns. This term describes a situation in which a whole town is entirely dependent on a single factory or an enterprise. The high concentration of migration flows from the east towards the centre and within the Moscow region is another driver of regional economic and demographic disparities. In addition, foreign workers have lower education levels than resident workers. Sub-national programs that explicitly target foreign workers with lower skill levels than the set at the national level and authorize cities and regions to manage this process actively are a solution whose effectiveness has been confirmed in various traditional migrant destinations. ${ }^{77}$ Therefore, the introduction and promotion of programs that would allow local authorities to recruit foreign workers with a lower level of skill than at the national level is recommended.

\subsection{Migrant diasporas as a supply factor in skill-selective programs}

A principal goal of the CSMP migration measures is to achieve a desirable skill and qualification composition for international economic migrants in Russia. The purpose of this section is to analyze the potential impact of diasporas as an important supply factor affecting migrant skill and qualification levels. It answers two questions: (1) Other conditions being equal, are diasporas likely to facilitate an inflow of more or less skilled migrants after the introduction of the CSMP?; and (2) What recommendations for policymakers can be made based on the answer to (1)?

Diasporas or networks are defined as the stock of immigrants from a certain country, ethnicity, language group, etc. that already resides in the migrant receiving country. The impact of diasporas on migration patterns is confirmed in the empirical literature. ${ }^{78}$ Beine et al. $(2010)^{79}$ study the diaspora effects based on macro data from the OECD for receiving countries. Their article reflects the perspective of emigration between industrial countries and from developing countries to industrial countries. The authors argue that migration networks are an externality that affects the migrant patterns (size, concentration, and skill composition) in the recipient country through two channels. The first channel is represented by migration policies that lower the legal requirements for migration. Its impact is referred to as the "visa effect." The second channel responsible for the "assimilation effect" consists of the reduction of information and assimilation costs for new immigrants who belong to the network. By assessing the combined effect of the two channels, the authors reach the conclusion that migrant networks lead to a negative selection of skilled immigrants (a faster increase in more unskilled 
immigrants), and that the size of the diaspora accelerates this process. Thus, the visa and/or the assimilation effect can be detrimental to the effectiveness of migration policies that select on the basis of skills and qualifications.

Furthermore, McKenzie and Rapoport (2010) ${ }^{80}$ study the role of the size of migration networks in shaping the self-selection decisions of Mexican migrants to the United States. They find that in Mexican communities with large networks, associated with small migration costs the probability of firsttime migration decreases with the level of education, which corresponds to negative self-selection. Conversely, in Mexican communities with weak migration networks and high migration costs, migrants from the upper middle level of the education distribution are chosen, which corresponds to positive self-selection.

Bertoli and Rapoport (2013) ${ }^{81}$ extend the work of McKenzie and Rapoport (2010) by studying the conditions under which an expansion of networks does not lead to an inflow of lower-skilled migrants. Their theoretical model predicts that if the expansion of migrant networks improves the incentive to invest in education, no deterioration of migrants' quality (skills and educational level) occurs. Bertoli et al. (2014) ${ }^{82}$ develop a theoretical model that shows that even if the increase of educated migrants is scale-invariant over time, their quality may deteriorate if the increasing restrictiveness of selective migrant policies based on migrants' observable characteristics influences migrants' selection on unobserved variables (for example, motivation). Furthermore, Bertoli and Fernández-Huertas Moraga (2012) ${ }^{83}$ demonstrate on the basis of a dataset of OECD countries that the immigration policy of other immigrant-receiving countries is a highly relevant factor when assessing the effect of migrant networks on bilateral migration flows.

In the context of the mentioned research, diasporas can be expected to play an important role in the process of implementing the CSMP in Russia. This statement is motivated by the geographical principle on which the discussed post-USSR Russian migration policy was based. The net migration balance for 2013 reveals that $93 \%$ of its official total originates from the CIS region. This highly concentrated migration structure has been strengthened in the post-USSR period by a progressive growth of illegal migration from the geographically near countries situated in Central Asia, the Caucasus, as well as China, North Korea, Vietnam, and Afghanistan. ${ }^{84}$ Over time, migrants have formed diaspora communities in Russia ${ }^{85}$ which represent their interests and may be expected to exert an influence on international economic immigration through the channels defined by Beine et al. (2010).

A supportive example for the diaspora argument can be seen in the stricter legal rules for the recruitment of highly-qualified migrants in the Russian retail sale sector that were approved in 2013. This legal amendment became necessary because of the rather broad definition of highly-qualified specialists, which was based on annual earnings and not on qualifications. According to 
the Federal Migration Service, every fifth highly-qualified migrant in Russia was engaged in trade activities; quota formalities were easy to circumvent via interventions by the employer (who usually originated from the same country as the immigration applicant and who guaranteed that the foreign employee would earn the salary of a highly-qualified specialist). ${ }^{86}$ As a result of these labor market distortions, since 2013 employers and commissioners have been prohibited from hiring highly-qualified specialists in retail sales in Russia.

Migrant networks in Russia are also a relevant factor in the recently introduced patents legislation for economic migrants from visa-free countries. According to the new 2015 patent rules, migrants must submit the necessary documents and file their patent application within 30 days from the date on which they arrive in Russia. Hence, the administrative formalities are entrusted to the foreign job applicants and must be completed within a considerably shorter period than the 90 days after arrival during which a migrant was previously allowed to stay in Russia without a work permit. Unattractive features of the patents are their price, the fact that payment must be made in advance without any guarantee of employment, and the fact that they are valid only within a certain federal entity of the Russian Federation. ${ }^{87}$ A possible effect of this legislative amendment is an increase in illegal immigration facilitated by diasporas because immigrants may not able to find an employer within this short period after their arrival in Russia.

In conclusion, diasporas are likely to influence the future migrant communities in the direction of negative skill selection because of the expected difficulties of complying with the recent patents requirements. Since current CIS migrants are less fluent in Russian and less qualified than previous generations of migrants ${ }^{88}$ and there was a lack of integration and adaptation programs for migrants in the pre-CSMP period, the assimilation effect may be expected to be of lower magnitude. Negative skill selection could instead materialize through the visa effect described in Beine et al. (2010), which relates to the CSMP measures that lower legal barriers for family reunions, for example, and the preferences given to those applying for permanent residence status and citizenship. Therefore, it is recommended that these measures be strictly controlled and limited as far as possible to migrants with a desired profile. It is also recommended that diaspora engagement policies are implemented as a complement to the main CSMP policies with a focus on international economic migrants.

\subsection{Demand-driven, multiple criteria-based labor market tests}

The new migration concept for Russia contains the general statement that labor market tests for determining the need for migrant labor, which will depend on the prospects for the development of the economy and the national 
labor market, are to be introduced. However, it does not contain a definition of the important concept of labor shortage, which impedes the transparent assessment of the effectiveness of this policy. Labor market tests and a definition of labor shortage imply that there are to be demand-driven state interventions. The purpose of this section is to present such rigorous practices of the Migration Advisory Committee (MAC), an independent public body that advises the UK government on migration issues, and to propose recommendations, based on practice in the UK.

$\mathrm{MAC}^{89}$ uses top-down (national statistical data) and bottom-up (information from stakeholders) evidence for assessment of job titles and occupations based on three tests: skilled, shortage, and sensible. The first test is motivated by the fact that unlike Australia and Canada, the United Kingdom limits employment to skilled foreign workers. Formal qualifications, earnings, and the skill level as per the Standard Occupational Classification hierarchy are procedures on which grounds MAC defines skilled occupations and skilled jobs within less skilled occupations. MAC works with two shortage concepts: static (temporary) ${ }^{90}$ and dynamic (when impediments limit wage adjustment flexibility). A job or an occupation is considered to be in shortage when both the top-down and the bottom-up approach provide evidence for it. The decision whether it might be sensible to recruit foreign workers for labor shortage is of crucial importance in MAC's methodology. Based on productivity, innovation, and competitiveness criteria, it provides an answer to the question if a labor shortage may be eliminated by training as an alternative to hiring economic immigrants. Thus, protection of the work places of resident workers and maintenance of their skill level is sought. Consequently, the benefit of the "sensible" criterion consists in the fact that it directly links migration and other public policy goals, such as education.

The introduction of a definition for "skill" in the CSMP context should facilitate the future assessment of its effectiveness. As pointed out by Ruhs (2011), " ${ }^{91}$ "[t]he term 'skills' is ambiguous and can be interpreted and operationalized in many different ways." In this regard, it is recommended that the existing broad legal definition of highly-skilled workers, in Article 13.2 of Federal Law No. 115-FZ of 25 June 2002, based on certain lower bounds of earnings, is reformed and linked to criteria such as level of work-related stress and (high) demand in order to identify precisely for each case whether a foreign worker's wage is below the market rate and whether displacement of resident workers occurs. Concerning the labor market tests in the context of the CSMP, the introduction of skilled, shortage, and sensible tests is recommended by considering a variant of the MAC's procedures. Skilled jobs within low-skilled occupations should be identified and monitored. 


\section{Summary of Recommendations}

The derived in Section 4 recommendations for Russia on the basis of the analysis of the effectiveness of the migration policies of other international economic migrant-receiving countries can be summarized as follows:

1) CSMP measures that lower the legal barriers to migrants should be strictly controlled, and limited as far as possible to migrants with a desired profile because diasporas may influence future migrant flows and communities in the direction of negative skill selection. The implementation of diaspora engagement policies is also recommended as a complementary measure to the main CSMP international economic migrant policies.

2) It is recommended to introduce skilled, shortage, and sensible tests as part of the CSMP, to identify and monitor skilled jobs within low-skilled occupations, and to reform the existing broad legal definition of highly-skilled workers, based on certain lower bounds of earnings. It is recommended that this is linked to criteria such as level of work-related stress and (high) demand in order to identify precisely for each case whether a foreign worker's wage is below the market rate and whether displacement of resident workers occurs.

3) It is recommended to consider the application of hybrid, supply-led, and/or demand-driven models for the selection of international economic migrants discussed above after increasing the attractiveness of the country for them.

4) It is recommended to make economic immigration applications eligible for expedited processing in cases of work experience in high-demand professions in Russia and where there is pre-arranged employment (or a job offer).

5) Consideration of the introduction of policy measures that enhance the adaptability of foreign graduates from study to work is recommended, with this transition process being coordinated among employers and state institutions.

6) It is recommended to include the possibility of allocating points for various levels of proficiency in the Russian language in the point-based parameters for obtaining permanent residence because language skills have been scientifically proven to be a factor that enhances the employability and integration of foreign workers in migrant receiving countries.

7) It is recommended to implement careful screening of foreign investors who apply for permanent residence under the points-based system in Russia because of the globally reported frequent ineffectiveness of fast pathways to citizenship for such international economic migrants. 
8) The introduction of a two-step procedure with transparent transition pathways that properly assesses the adaptability of temporary (highly-)skilled foreign workers and international graduates during its first stage and offers them permanent residence with more rights during its second stage in order to reduce the likelihood of their emigration is recommended.

9) It is recommended to consider the introduction of a variant of the UK practice that entails employer licensing for more vulnerable groups of foreign workers, such as lower-skilled, foreign students and foreign graduates from Russian universities.

10) It is recommended to consider sub-national programs that explicitly target foreign workers with skill levels lower than the national level and to allow local authorities to manage this process actively.

\section{Conclusions}

Russia's strategy for attracting and retaining the best talent has only recently been placed on its state migration agenda for skill- and knowledge-based economic development as part of the Concept of the State Migration Policy for the period 2012-2025. With the ambitious goal of changing its role from a less traditional, global immigration destination to a winner in the global competition for value-added migration, Russia has set itself a forward-looking goal with strong emphasis on both the direct import of talent from abroad and the transfer of migrants from existing temporary categories. In addition to relevant international experience, two concepts should be considered for the planned assessment of the effectiveness of the CSMP on its third stage (2021-2025): (1) data quality and availability, and (2) appropriate research methods.

Data quality and availability in the context of the recommended application of the theoretical model of Czaika and de Haas $(2013)^{92}$ is essential because comparison of policy variables, such as volume, composition, timing, and direction of migrants before and after a change in the particular migration legislation must be considered. This process involves a subjective judgment for the strength of the desired (intended) policy effect, while taking into consideration other factors that may influence or entirely mask the policy variables (unintended, or substitution effects). ${ }^{93}$ An example of the application of the model of Czaika and de Haas (2013) that illustrates these effects is the study by Emilsson (2015) ${ }^{94}$ The author analyzed the outcome of a change to migration policy in Sweden in 2008 , when the state transferred to individual employers the power to select economic migrants. Thus, the Swedish model for the selection of such migrants became employer-led. Emilsson (2015) assesses this migration reform as ineffective because eco- 
nomic migrants increased in surplus occupations and not in shortage occupations, as was the state policy goal. A further example of unintended immigration policy effects is Emilsson et al. (2014). ${ }^{95}$ The authors state that many immigrants who obtained a visa to Sweden after the 2008 reform by declaring employment as a reason for their trip applied for asylum after entering the country.

Three points can be made with regards to the examples provided and the recommended application of the model of Czaika and de Haas (2013) on the third stage of the CSMP when its effectiveness is assessed. First, the right categories of migrants must be selected in order to evaluate whether a migration policy has achieved the desired (intended) result. This strategy entails giving an answer to the question of whether the written policy objectives are general (addressing the overall volume and composition of immigrants) or specific (focused on specific immigrant groups, usually under different immigration regimes). ${ }^{96}$ Second, good quality data, available for a sufficiently long period, should make it possible to make a systematic assessment of the effectiveness of both the specific and the general objectives of a migration policy. The planned assessment in 2021-2025 of migration measures introduced during the CSMPs first (2012-2015) and second (2016-2020) stages would be performed after a relatively short time. Consequently, if the necessary data exists, short-run effects that may be quite different from long-run effects may be detected. Third, the specifics for the methodological compatibility and comparability of CSMP-relevant migrant data (for example, sources, collection, and aggregation) must be considered.

With respect to the latter point, it is relevant to consider the discussed Russian legal regimes which depend on whether the foreign worker arrives from a visa-free or a visa-requiring country. Apart from the explicit goal of increasing foreign students from the CIS region, the CSMP does not have any concrete goals concerning the origin of international economic migrants. However, a natural division of foreign workers for the assessment of its outcomes would be according to whether they arrived from a visa-free or a visa-requiring country, because of their different legal treatment. Specifically, as of 1 January 2015, the Russian government ${ }^{97}$ assesses the need for the recruitment of foreign workers and the number of work permits only with respect to migrants from visa-requiring countries. However, such migrants constitute a tiny minority of all arrivals, with the majority coming from a visa-free country. These migrants predominantly originate from the CIS countries and, as of 1 January 2015, are subject to a patent issuance regime. The regions of Russia decide on the number of patents to be allocated. Therefore, the data relating to the market tests for visa-free and visarequiring migrants, which must be collected from different sources, should be made available in a methodologically compatible and comparable form, for example by the Federal State Statistical Service. 
Migration policies involve considerable budget costs. Not only are the inflows of international economic migrants of considerable importance, but their outflows are as well. Therefore, the availability of a statistical database for the priority CSMP groups of international economic migrants, such as members of professions that are in high demand like IT specialists, including emigrant volume, composition, direction, timing, and reasons for leaving Russia, may reveal early warning signals for the real and desired outcomes of Russia's migration policies.

A principal question that is addressed by research methods in the assessment of the effectiveness of a migration policy is the identification of the intended migration policy outcome. Czaika and de Haas $(2013)^{98}$ recommend that public policy discourses (politicians' stated objectives) are not considered as the desired outcome because they may deviate from written policies. These authors provide a methodological overview of two alternative quantitative estimation techniques for assessing migration policy effectiveness. The first is a binary migration policy ("dummy") variable to mark the time of the introduction of a particular migration policy change, which should capture only its specific effects. The second one is a migration policy index. As the main drawbacks to this, the authors put forward its subjective weighting and aggregation, its loss of information if all policy components are summarized in a single, generalized measure, and the difficulty arising from trying to relate a result to a specific migration policy outside all other influencing factors (the attribution problem). Finally, since it is essential to understand the concrete context in which migration policies are designed and implemented, quantitative studies on the factors that affect migration should be combined with qualitative methods. ${ }^{99}$ 
Appendix 1 Population and migration statistics of Russia ${ }^{100}$

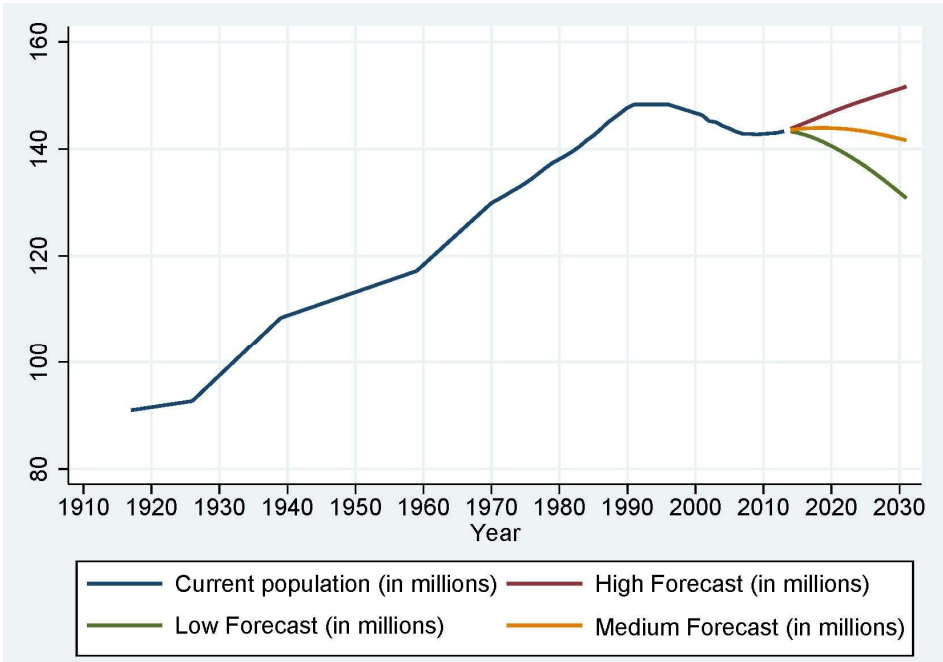

Figure 1 This figure presents the dynamics of the population of the Russian Federation in the period 1917-2013, as well as three forecasts (high, medium, and low) for its evolution in the period 2014-2031. It can be observed that, in the years after the dissolution of the Soviet Union in 1991, a tendency towards a decrease in the population has begun, and that this has been slightly reversed only recently. Data source: Federal State Statistics Service of the Russian Federation.

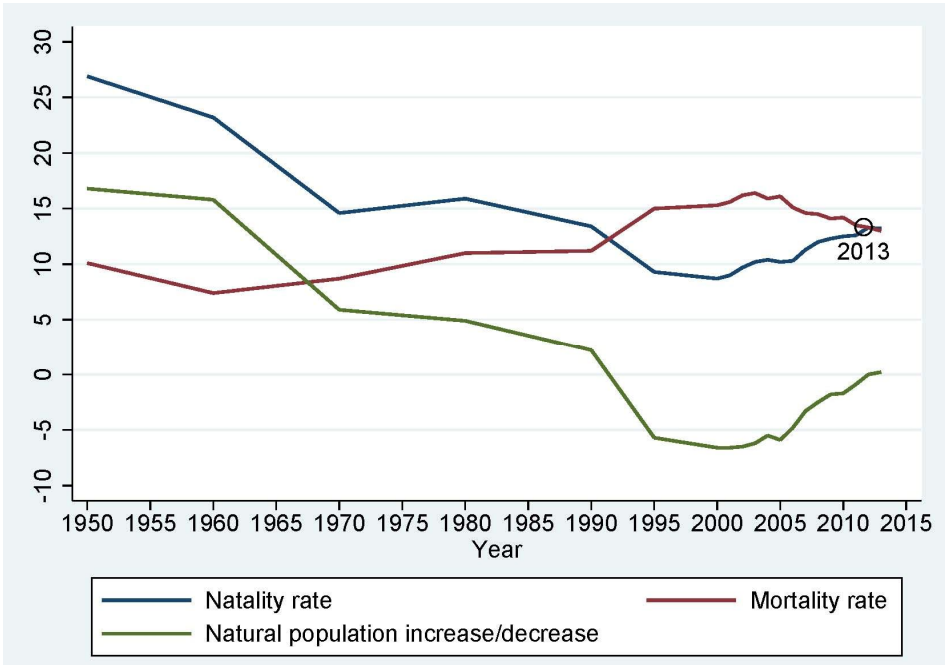

Figure 2 This figure presents the dynamics of the birth and mortality rates per 1,000 people in the Russian Federation. The variable Natural population increase/decrease is calculated as the difference between the natality rate and the mortality rate for each available annual observation in the data set for the period 1950-2013. It does not take into account migration flows. It can be observed that, after the dissolution of the Soviet Union, the birth rate exceeded the mortality rate for the first time in 2013. Data source: Federal State Statistics Service of the Russian Federation. 


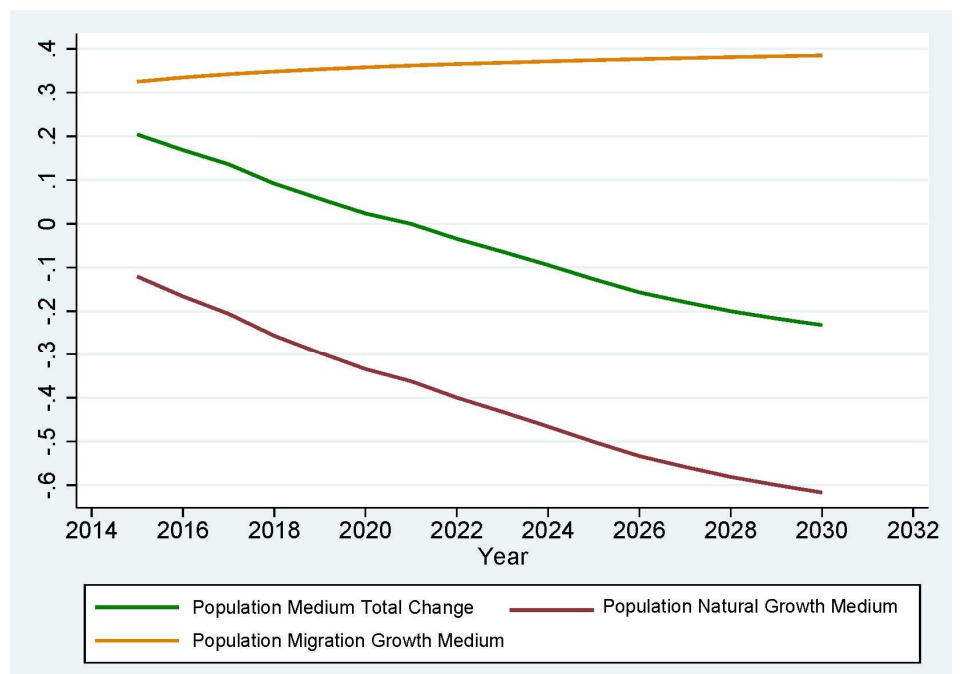

Figure 3 This figure presents a medium scenario for the forecast as of 26 August 2014 of the Federal State Statistics Service of the Russian Federation for the dynamics of the average change in the population in the period 2015-2031. All variables are measured in millions. The variable "Population Migration Growth Medium" is the official medium forecast for the net migration balance. The variable "Population Natural Growth Medium" is the official medium forecast for the variable Natural population increase/decrease in Figure 2. The variable "Population Medium Total Change" is the sum of "Population Migration Growth Medium" and "Population Natural Growth Medium" for each available annual observation in the data set for the period 2015-2031. It can be observed that the negative future trend of the variable "Population Medium Total Change" is expected to be partially offset by immigration growth. Data source: Federal State Statistics Service of the Russian Federation.

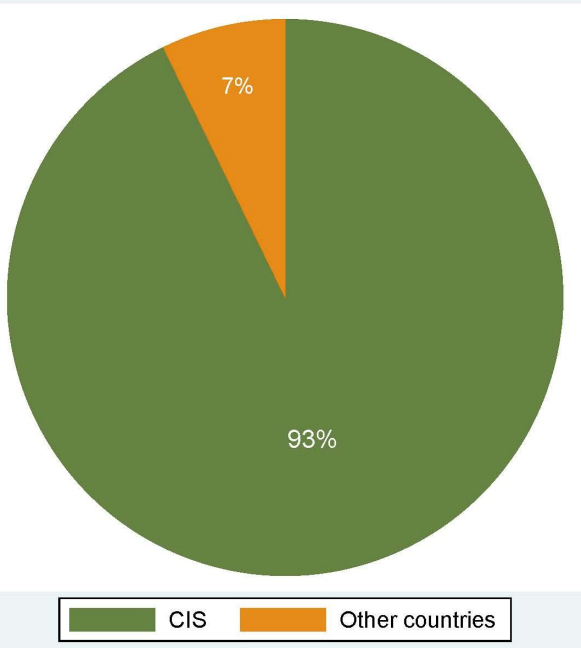

Figure 4 This figure presents the total net migration balance in Russia (defined as the difference between the total incoming and the total outgoing migrants and reported separately for CIS and other countries) in 2013. Data source: Federal State Statistics Service of the Russian Federation. 


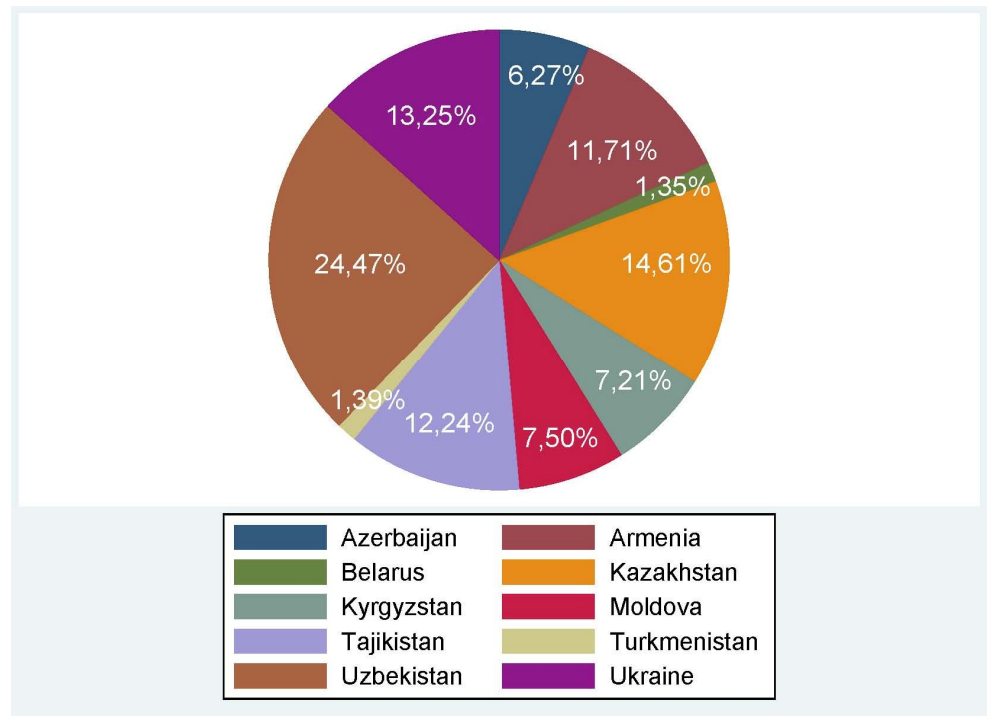

Figure 5 This figure presents a breakdown of net migration for the CIS (the difference between the total number of incoming and the total number of outgoing migrants) for 2013, because this region accounted for 93\% of the total net migration balance in 2013 (see Figure 4). Data source: Federal State Statistics Service of the Russian Federation.

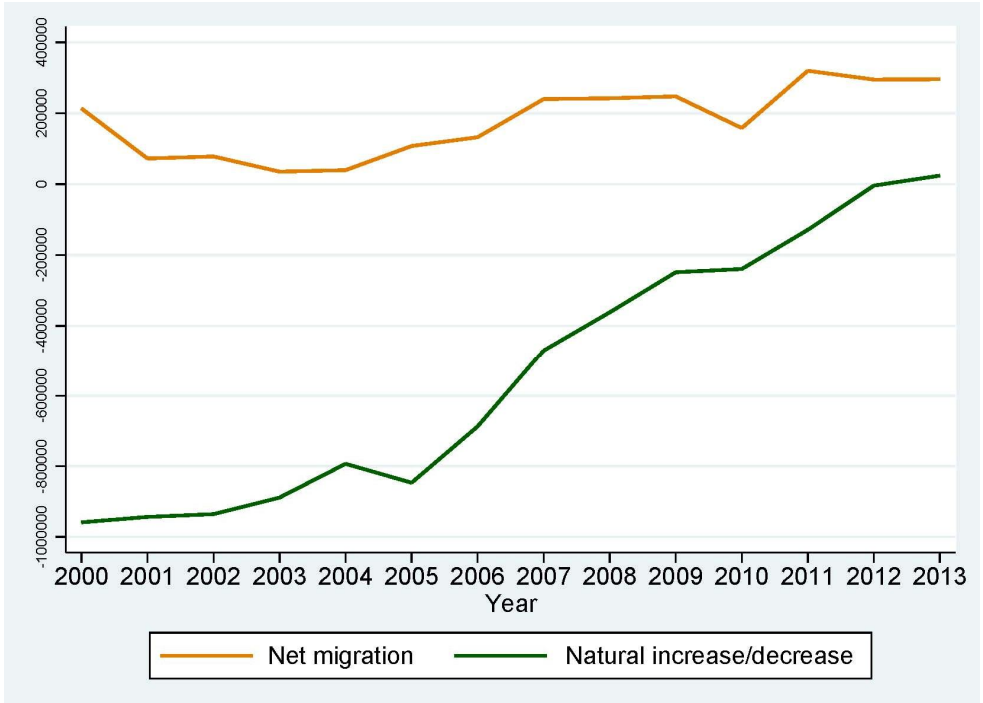

Figure 6 This figure presents the net migration and the natural increase/decrease in the population of the Russian Federation in the period 2000-2013. Data source: Federal State Statistics Service of the Russian Federation. 


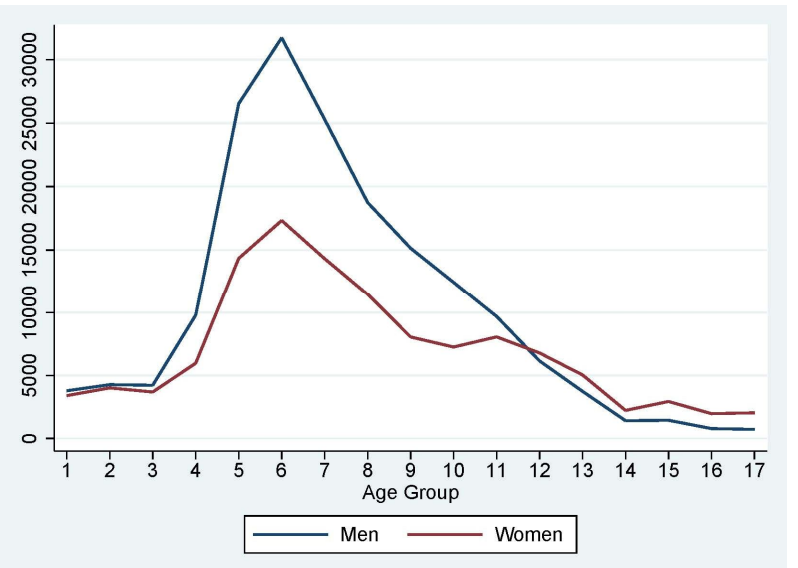

Figure 7 This figure presents the age distribution of the net migration of men and women in 2012. Age groups: (1) for 0-4 years, (2) for 5-9 years, (3) for 10-14 years, (4) for 15-19 years, (5) for 20-24 years, (6) for 25-29 years, (7) for 30-34 years, (8) for 35-39 years, (9) for 40-44 years, (10) for 45-49 years, (11) for 50-54 years, (12) for 55-59 years, (13) for 6064 years, (14) for 65-69 years, (15) for 70-74 years, (16) for 75-79 years, and (17) for 80+ years. Data source: Federal State Statistics Service of the Russian Federation.

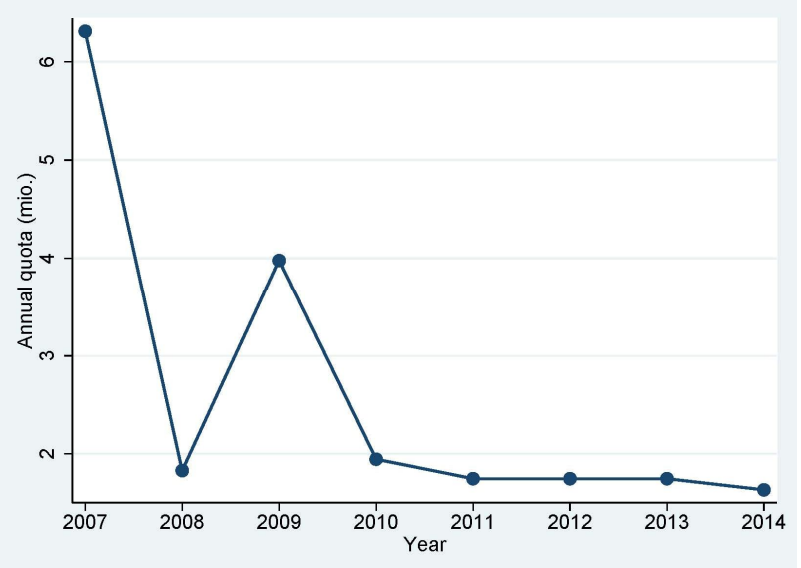

Figure 8 This figure presents the initial annual total quotas for work permits for foreign workers for each year in the period 2007-2014. As of 1 January 2015, work permits and quotas for work permits for foreign nationals from visa-free countries were replaced by patents. Data sources: Ministry of Healthcare of the Russian Federation, Order N 1008 of 22.12.2009, http://www.consultant.ru/document/cons_doc_LAW_105653/?frame=1, Ria Novosti (2 November 2011). Strategy 2020: In Russia must be created a Ministry for Migration, http://strategy2020.rian.ru/news/20111102/366193197.html, Rossiysaya Gazeta, Federal Issue 5341 of 19 November 2010, Decree No. 895 of 12 November 2010, http://www.rg.ru/2010 /11/19/rabota-dok.html, Decree No. 892 of 3 November 2011, http://www.consultant.ru/law/ review/1219375.html, Decree No. 1137 of 3 November 2012, http://www.rg.ru/2012/11/09/ kvoty-dok.html, Decree No. 977 of 31 October 2013, http://www.rg.ru/2013/11/05/quots-sitedok.html, Gradirovski, S. (2010), "Politics of Repatriation and Labor Migration in the Modern Russian State," http://www.archipelag.ru/download/book/text_pdf/doklad_vb_2010/02_trud.pdf [Accessed: 15 January 2016]. 

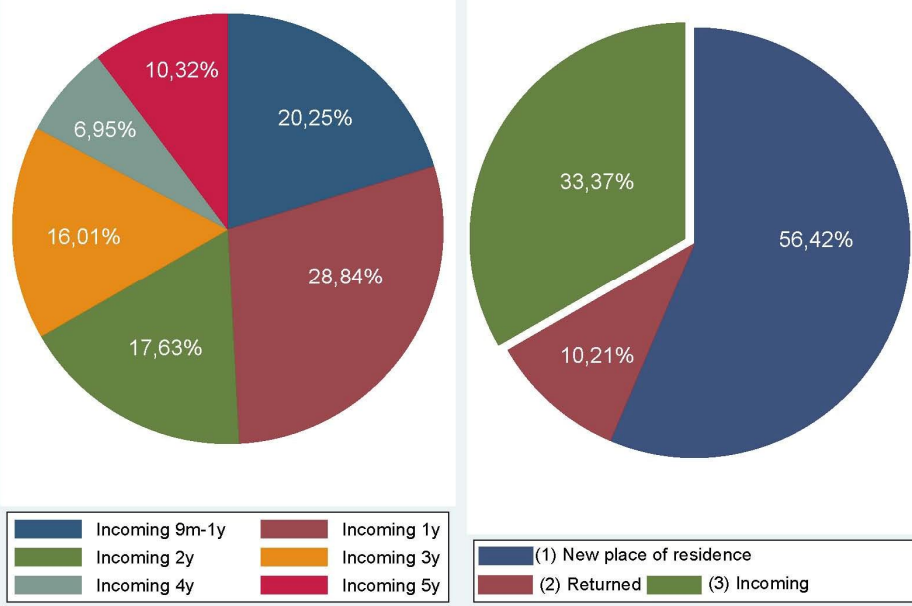

Figure 9 This figure presents the number of arrivals by types and terms of registration in 2012. The right-hand panel presents the following: the number of arriving people who were registered in a new place of residence / domicile (variable (1) New place of residence); the number of people who returned to their place of residence after a temporary absence (variable (2) Returned); and the number of arriving people who were registered in a place of residence (variable (3) Incoming). The left-hand panel presents a further breakdown of the variable (3) Incoming depending on the duration of the stay: $9 \mathrm{~m}-1 \mathrm{y}$ (from 9 months to 1 year), $1 \mathrm{y}$ (1 year), $2 \mathrm{y}$ ( 2 years), $3 y$ (3 years), $4 \mathrm{y}$ (4 years), and $5 \mathrm{y}$ (5 or more years). Data source: Federal State Statistics Service of the Russian Federation.

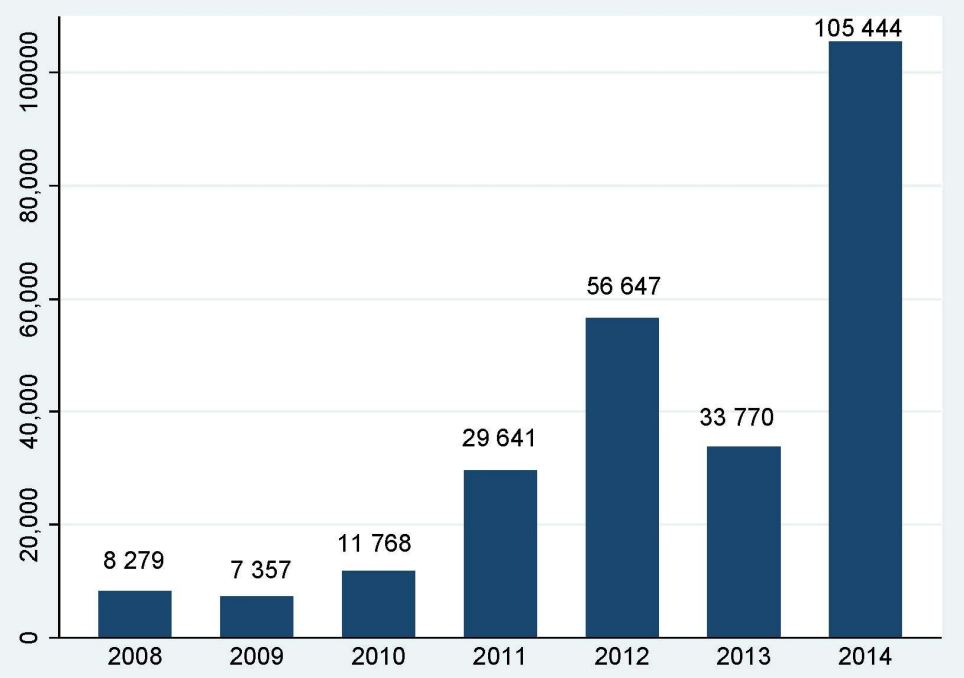

Figure 10 This figure presents the annual number of participants (including members of their families) in the state program for facilitating the voluntary resettlement of compatriots living abroad in the Russian Federation. Data source: Federal State Statistics Service of the Russian Federation. 
Table 1 Educational level of incoming migrants (immigrants) in 2013

\begin{tabular}{l|llllllll}
\hline & $(1)$ & $(2)$ & $(3)$ & $(4)$ & $(5)$ & $(6)$ & $(7)$ & $(8)$ \\
\hline CIS (in \%) & 12.77 & 2.13 & 21.98 & 2.35 & 32.59 & 6.36 & 1.65 & 20.18 \\
Other countries (in \%) & 14.40 & 2.47 & 15.89 & 2.13 & 29.57 & 3.79 & 1.30 & 30.44 \\
\hline
\end{tabular}

Data source: Federal State Statistics Service of the Russian Federation.

Abbreviations: (1) higher vocational education; (2) incomplete (not fully completed) higher vocational education; (3) secondary vocational education; (4) primary vocational education; (5) secondary general education; (6) primary general education; (7) without education or with initial general education; (8) not indicated.

Table 2 This table contains the second draft of the Resolution of the Government of the Russian Federation "On the point system of selection of foreign nationals and stateless persons wishing to obtain a permit for permanent residence in the Russian Federation," dated 8 September 2015 and published on the Federal portal for drafts of legal acts, Project ID: 01/01/08-15/00039144, http://regulation.gov.ru/projects\#npa=39144 and http://base.consultant.ru/cons/cgi/online.cgi? req=doc;base=PNPA;n=11419; div=PRJ;diff=11723;from=11419$131 ;$ rnd=184768.630623483331874. The minimum passing score for obtaining permanent residence in the Russian Federation by foreign citizens and stateless persons is set at 65 points.

Criterion

1. Age

2. Education

3. Work experience with qualification as per the obtained educational or qualification document ${ }^{102}$

4. Work experience in professions, specializations, or directions that are in high demand ${ }^{103}$ on the Russian labor market

5. Labor or entrepreneurship activity in Russia ${ }^{104}$

6. Existence of close relatives that are Russian citizens

7. Ownership of housing on

Russian territory

8 . Investor with a share not less than $10 \%$ in a Russian entity in a time span of 3 years starting from the investment date, ${ }^{105}$ who undertakes indicated by the Russian Government economic activities

9. Sole trader, ${ }^{106}$ who undertakes indicated by the Russian

Government economic activities

\section{Parameter value}

Up to 18 years

Older than 18 years and up to 21 years

Older than 21 years and up to 45 years

Older than 45 years and up to 55 years

Older than 55 years

Lower than primary general education

Primary general education

Secondary general education

Secondary vocational education

Higher education

Less than 1 year

From 1 year to 3 years

From 3 to 5 years

More than 5 years

Up to 1 year

From 1 year to 3 years

More than 5 years

Absent

Less than 1 year

From 1 year to 5 years

More than 5 years

yes

no

yes

no
Allocation of

points

12 points

18 points

20 points

12 points

0 points

0 points

5 points

15 points

25 points

$30(35)^{101}$ points

0 points

5 points

8 points

15 points

15 points

20 points

25 points

0 points

3 points

7 points

15 points

5 points

0 points

5 points

0 points

50 points

40 points 


\section{Acknowledgements}

The author is grateful to Professor Alia Gizatulina, Professor Simon Evenett and three anonymous reviewers for their feedback. The views expressed in this article are solely those of the author, and do not necessarily reflect the views of the University of St. Gallen.

\section{NOTES AND REFERENCES}

1. UN-DESA and OECD (2013), "World Migration in Figures." Available from: http://www.oecd.org/els/mig/World-Migration-in-Figures.pdf [Accessed: 15 January 2016].

2. Popov, N. P. (2012), "Is Russia Dying Out?" Herald of the Russian Academy of Sciences 82(1): 1-7.

3. President of the Russian Federation, "The President Approved the Concept of State Migration Policy of the Russian Federation for the Period up to 2025." Available from: http://kremlin.ru/news/15635 [Accessed: 15 January 2016].

4. See points 11, 13 and 14 of "The Concept of the State Migration Policy of the Russian Federation until 2025."

5. Before the introduction of the CSMP, this state program had been the only one that targeted permanent settlement in a selected list of Russian regions. As of 1 July 2015, it has been implemented in 58 out of 85 top-level political divisions, defined according to the Constitution of Russia. Monitoring of the realization of the State Program for the second quarter of 2015. Available from: http://www. fms.gov.ru/ fms/compatriots/ [Accessed: 15 November 2015].

6. Czaika, M., and H. De Haas (2013), "The Effectiveness of Immigration Policies," Population and Development Review 39(3): 487-508.

7. Castles, S. (2012), "The Factors That Make and Unmake Migration Policies," International Migration Review 38(3): 852-884.

8. Ibid.

9. Czaika, M., and H. De Haas (2013), “The Effectiveness of Immigration Policies."

10. Czaika, M., and H. De Haas (2011), "The Effectiveness of Immigration Policies. A Conceptual Review of Empirical Evidence," University of Oxford, Working Paper No. 33. Available from: http://www.imi. ox.ac.uk/pdfs/wp/wp-3311.pdf [Accessed: 15 January 2016].

11. Lowell, L. B. (2005), "Policies and Regulations for Managing Skilled International Migration for Work," United Nations Expert Group Meeting on International Migration and Development, New York, 6-8 July, Department of Economic and Social Affairs, UN/POP/MIG/2005/03, and Koslowski, R. (2014), "Selective Migration Policy Models and Changing Realities of Implementation," International Migration 52(3): 26-39.

12. The term "economic migrant" is defined by the International Organization for Migration as: "[a] person leaving his or her habitual place of residence to settle outside his or her country of origin in order to improve his or her quality of life. This term is often loosely used to distinguish from refugees fleeing persecution. [...] It may equally be applied to persons leaving their country of origin for the purpose of 
employment." Available from: http://www.iom.int/cms/en/ sites/iom/home/aboutmigration/key-migration-terms-1.html\#economic-migrant [Accessed: 15 January 2016].

13. Different migration categories do not exist in a pure form. For example, economic migrants may arrive with members of their family. Hence, economic migration is related to family migration. Therefore, whenever applicable, relevant additional migrant categories will be analyzed in connection with the purpose of this paper, economic migrants.

14. State policies' effectiveness towards illegal migrants will not be analyzed in this study.

15. Point 4 of the schedule of migration policy legislation for the period 20122015 in Resolution No. 1502 of 21 August 2012 foresees two such state programs, namely a program for the seasonal migration of workers and the organized recruitment of foreign workers, and a program for the holiday employment of foreign students. Available from: http://pravo.gov.ru/proxy/ips/?docbody $=\& n d=102158863 \&$ intelsearch $=21+\% \mathrm{E} 0 \% \mathrm{E} 2 \% \mathrm{E} 3 \% \mathrm{~F} 3 \% \mathrm{~F} 1 \% \mathrm{~F} 2 \% \mathrm{E} 0+2012+\% \mathrm{E} 3 \% \mathrm{EE} \% \mathrm{E} 4 \% \mathrm{E} 0+\mathrm{N}+1$ 502-\%F0 [Accessed: 15 January 2016].

16. Karachurina, L. B. (2012), "Permanent Migration between Russia and CIS Countries," Demoscope Weekly No. 535536, 1031 December [online]. Available from: http://demoscope.ru/weekly/2012/0535/analit05.phpFNR9 [Accessed: 15 January 2016].

17. Ibid.

18. Federal State Statistics Service of the Russian Federation, Number and Migration of the Population of the Russian Federation in 2014. Available from: http://www.gks.ru/bgd/regl/b15_107/ [Accessed: 15 January 2016].

19. Rossiysaya Gazeta, Federal Issue of 5704 of 14 February 2012, Population Saving. Vladimir Putin spoke about his vision concerning social problems [online]. Available from http://www.rg.ru/2012/02/14/putin.html [Accessed: 15 January 2016].

20. Nationals from certain countries (for example, Chile, Colombia, Cuba, Nicaragua, Israel, and Serbia) with which Russia has signed an international agreement benefit from a similar to visa-free countries status.

21. Federal Law 221-FZ of 21 July 2014 that entered into force on 1 January 2015, which amended Article 333.28, point 17, 23, and 24 of the Tax code of the Russian Federation. Available from: http://www. consultant.ru/document/cons_doc_ LAW_28165/2c9d3e23bb4c55026a2d6869494e63db3d3d339a/. The minimal salary for 2015 was introduced by Federal Law No. 408-FZ of 1 December 2014. Available from: http://www.consultant.ru/law/ref/stavki/soc-sfera/mrot/ [Accessed: 15 January 2016].

22. Rossiysaya Gazeta, Federal Issue 5660 of 16 December 2011, “On the Results of the National Population Census 2010." Available from http://www.rg.ru/2011/12/ 16/stat.html [Accessed: 15 January 2016].

23. Vlasova, N. (2012), "Legalisation of the Illegal Migrants: Actual Questions and Risks," Migration of the 21st Century 2(11): 32-33. Available from: http:// mirpal.org/files/files/migraciaXXI-11n-(2012).pdf [Accessed: 15 January 2016].

24. Balykov, V. N. (2009), "Delinquency of Foreign Nationals and Stateless Persons Based on Materials from Moscow and the Moscow Region." Available from: http://law.edu.ru/book/book.asp?bookID=1357782 [Accessed: 15 January 2016]. 
25. Levada Analytical Centre (2011), "Public Opinion 2011." Available from: http://www.levada.ru/old/sites/default/files/levada_2011_0.pdf [Accessed: 15 January 2016].

26. Levada Analytical Centre (2011), "Nationalism in Russia." Available from: http://www.levada.ru/26-09-2011/natsionalizm-v-rossii [Accessed: 15 January 2016].

27. Levada Analytical Centre (2011), "Public Opinion 2011." Available from: http://www.levada.ru/old/sites/default/files/levada_2011_0.pdf [Accessed: 15 January 2016].

28. Highly-qualified specialists, broadly defined as individuals with certain lower bounds of earnings, are excluded from the scope of the quotas, as well as the documentary formalities for foreign workers from visa-free and visa-requiring countries. The legal basis is article 13.2 of Federal Law No. 115-FZ of 25 July 2002 "On the legal status of foreigners in the Russian Federation." Available from: https://www. consultant.ru/document/cons_doc_LAW_37868/a605996320180cd7015eadeb1564d e9768fffadd/ and http://www.fms.gov.ru/info/FAQ/item/18164/6/. [Accessed: 15 January 2016]

29. Czaika, M., and H. De Haas (2013), “The Effectiveness of Immigration Policies."

30. Federal Law No. 357 of 24 November 2014. Available from: http://www. rg.ru/2014/11/27/inostr-dok.html [Accessed: 15 January 2016].

31. Ibid.

32. Rossiyskaya Gazeta, Capital Issue No. 5928 of 2 November 2012, "Illegal Migration to Be Limited by New Laws." Available from: http://www.rg.ru/2012/ 11/02/mirazia-site.html [Accessed: 15 January 2016].

33. Ibid.

34. Tyuryukanova, E. (2005), "Forced Labour in Contemporary Russia: Irregular Migration and Human Trafficking," International Labour Organisation. Available from: http://www.ilo.org/wcmsp5/groups/public/---ed_norm/---declaration/documents /publication/wcms_081997.pdf [Accessed: 15 January 2016].

35. Ibid.

36. Federal Law No. 185-FZ of 12 November 2012. Available from: http:// www.rg.ru/2012/11/14/izmenenniya-dok.html [Accessed: 15 January 2016].

37. Federal Law No. 74-FZ of 20 April 2014. Available from: http://www.rg.ru/ 2014/04/23/inostrantsy-dok.html [Accessed: 15 January 2016].

38. "Concept of the State Migration Policy until 2025." Available from: http:// kremlin.ru/news/15635 [Accessed: 15 January 2016].

39. Employment contracts with foreign workers, regardless of their labor activity, have been limited to a period of one year (point 14, CSMP).

40. In the CSMP, the notion of "directions" is used, substituted by the term "policy trajectories" in this study.

41. The legislative acts for this stage are approved by Resolution No. 1502 of 21 August 2012 of the Government of the Russian Federation. Available from: http:// pravo.gov.ru/proxy/ips/?docbody $=\& n d=102158863 \&$ intelsearch $=21+\% \mathrm{E} 0 \% \mathrm{E} 2 \% \mathrm{E} 3$ $\% \mathrm{~F} 3 \% \mathrm{~F} 1 \% \mathrm{~F} 2 \% \mathrm{E} 0+2012+\% \mathrm{E} 3 \% \mathrm{EE} \% \mathrm{E} 4 \% \mathrm{E} 0+\mathrm{N}+1502-\% \mathrm{~F} 0$ [Accessed: 15 January 2016]. The relevant legislation from this stage is considered and discussed in this study. 
42. The legislative acts for this stage are approved by Resolution No. 2122 of 22 October 2015 of the Government of the Russian Federation. Available from: http:// government.ru/docs/20219/ [Accessed: 15 January 2016].

43. Czaika, M., and H. De Haas (2013), "The Effectiveness of Immigration Policies."

44. In order to facilitate their presentation, the international economic migrant policies have been grouped by the author in three categories. In the original CSMP text, they are distributed in different sub-headings.

45. In this regard, the Russian government has approved Resolution No. 257 of 20 March 2015. It sets the conditions and requirements for estimating the demand for work permits for foreign workers from visa-requiring countries. Migrants from visa-free countries, who account for the vast majority of foreign workers (see Figure 4), have not been subject to such labor market tests since 1 January 2015. Among the key new criteria for the employment of foreign workers from visa-requiring countries are: (i) an inability to meet the domestic labor demand, even with labor reallocation within the regions or the top-level political divisions of Russia; and (ii) compliance with the admissible share of foreign workers involved in various economic activities, for example, the retail trade and sports.

46. Federal Law No 203-FZ of 23 July 2013 of the Russian Federation introduces these amendments.

47. Czaika, M., and H. De Haas (2013), "The Effectiveness of Immigration Policies."

48. Ibid.

49. Marshall, R. (2011), "Value-Added Immigration. Lessons for the United States from Canada, Australia, and the United Kingdom," Economic Policy Institute. Available from: http://www.epi.org/publication/value-added-immigration [Accessed: 15 January 2016].

50. Ibid.

51. Ibid.

52. UN-DESA and OECD (2013), "World Migration in Figures" [online]. Available from: http://www.oecd.org/els/mig/World-Migration-in-Figures.pdf [Accessed: 15 January 2016].

53. See, e.g., Abadie, A., A. Diamond, and J. Hainmueller (2015), "Comparative Politics and the Synthetic Control Method," American Journal of Political Science 59(2): 495-510.

54. The terms "a hybrid model" and "a hybrid case" are used interchangeably in this article.

55. Doomernik, J., R. Koslowski, and D. Thränhardt (2009), "The Battle for the Brains: Why Immigration Policy Is Not Enough to Attract the Highly Skilled," German Marshall Fund of the United States. Available from: http://www.gmfus.org [Accessed: 15 January 2016].

56. Ibid.

57. Papademetriou, D. G., and M. Sumption (2011), "Rethinking Points Systems and Employer-selected Immigration," Migration Policy Institute. Available from: www.migrationpolicy.org/pubs/rethinkingpointssystem.pdf [Accessed: 15 January 2016].

58. Ibid. 
59. Ibid.

60. Although according to UN-DESA and OECD (2013) Russia is the second largest destination of migrants, its competitiveness in the global contest for valueadded migration is lower compared to traditional migrant destinations such as Australia, Canada, and the United Kingdom. This fact is also acknowledged by the CSMP and is one of the reasons for its introduction: "the attractiveness of the Russian Federation as a migration destination is not big compared to other receiving countries and is mainly valid for citizens of the states participating in the Commonwealth of Independent States" (point 9, CSMP).

61. Both drafts of the Resolution of the Government of the Russian Federation "On the point system of selection of foreign nationals and stateless persons wishing to obtain a permit for permanent residence in the Russian Federation" can be retrieved at: http://base.consultant.ru/cons/cgi/online.cgi?req=doc;base=PNPA;n= 11419; div=PRJ;diff=11723; from=11419-131;rnd=184768.630623483331874 [Accessed: 15 January 2016].

62. Marshall, R. (2011), "Value-Added Immigration. Lessons for the United States from Canada, Australia, and the United Kingdom."

63. Sumption, M., and K. Hooper (2014), "Selling Visas and Citizenship. Policy Questions from the Global Boom in Investor Immigration," Migration Policy Institute. Available from: http://www.migrationpolicy.org/sites/default/files/publications/Investor-Visas-Report.pdf [Accessed: 15 January 2016].

64. The most desirable age as per the second draft of the Russian point-based model for obtaining of permanent residence is between 21 and 45 years.

65. Secondary general education is chosen for the example because, as demonstrated in Table 1 based on recent statistical data, this is the most frequent educational level of CIS foreign workers who constitute the majority of net migration.

66. Sumption, M., and K. Hooper (2014), "Selling Visas and Citizenship. Policy Questions from the Global Boom in Investor Immigration."

67. Matloff, N. (2013), "Are Foreign Students the 'Best and Brightest'?: Data and Implications for Immigration Policy," Economic Policy Institute, Briefing Paper No. 356. Available from: http://www.epi.org/publication/bp356-foreign-students-bestbrightest-immigration-policy [Accessed: 15 January 2016].

68. Ibid.

69. Salzman, H., D. Kuehn, and B. L. Lowell (30 May, 2013), "Current and Proposed High-skilled Guest Worker Policies Discourage STEM Students and Grads from Entering IT," Economic Policy Institute, Economic Snapshot. Available from: http://www.epi.org/publication/current-proposed-high-skilled-guestworker/ [Accessed: 15 January 2016].

70. Research Unit of the Expert Council of German Foundations on Integration and Migration (2015), "Train and Retain. Career Support for International Students in Canada, Germany, the Netherlands, and Sweden." Available at http://www.svrmigration.de/wp-content/uploads/2015/08/Study_Train-and-Retain_SVR-researchunit_WEB.pdf [Accessed: 15 January 2016].

71. Ruhs, M. (2011), "Openness, Skills and Rights: An Empirical Analysis of Labour Immigration Programmes in 46 High- and Middle-income Countries," University of Oxford, Centre on Migration, Policy and Society, Working Paper No. 88. Available from: http://www.compas.ox.ac.uk/2011/wp-2011-088_ruhs_migrants 
_rights_full/ [Accessed: 15 January 2016]. The countries analyzed in the study are: Norway, Switzerland, Denmark, Sweden, Netherlands, Ireland, Finland, the United States of America, Austria, United Kingdom, Belgium, Germany, France, Canada, Australia, Kuwait, Japan, Italy, Singapore, Spain, Hong Kong, Greece, New Zealand, Israel, Slovenia, Republic of Korea, Portugal, Taiwan, United Arab Emirates, Czech Republic, Saudi Arabia, Slovak Republic, Hungary, Oman, Poland, Mexico, Turkey, Venezuela, Brazil, Argentina, Malaysia, Colombia, Dominican Republic, China, Thailand and Indonesia.

72. See, e.g., OECD (December 2014), "Who Should Be Admitted as a Labour Migrant?" Migration Policy Debates No. 4. Available at: http://www.oecd.org/ migration/migration-policy-debates-4.pdf [Accessed: 15 January 2016].

73. Marshall, R. (2011), "Value-Added Immigration. Lessons for the United States from Canada, Australia, and the United Kingdom."

74. See, e.g., Helbling, M., and H. Kriesi (2014), "Why Citizens Prefer Highover Low-Skilled Immigrants. Labor Market Competition, Welfare State, and Deservingness," European Sociological Review 30(5): 595-614; Hainmueller, J. and D. J. Hopkins (2015), "The Hidden American Immigration Consensus: A Conjoint Analysis of Attitudes toward Immigrants," American Journal of Political Science 59(3): 529-548.

75. Marshall, R. (2011), "Value-Added Immigration. Lessons for the United States from Canada, Australia, and the United Kingdom."

76. Thomson Reuters, http://findlaw.co.uk/law/immigration_emigration/sponsoring_migrants/sponsors_and_ratings/23578.html [Accessed: 15 January 2016].

77. Sumption, M. (2014), "Giving Cities and Regions a Voice in Immigration Policy. Can National Policies Meet Local Demand?" Migration Policy Institute. Available from: http://www.migrationpolicy.org/sites/default/files/publications/ TCM_Cities_National\%20Policy_FINALWEB.pdf [Accessed: 15 January 2016].

78. Beine, M., F. Docquier, and C. Özden (2010), "Diaspora Effects in International Migration: Key Questions and Methodological Issues," CREA Discussion Paper Series 10-14, Center for Research in Economic Analysis, University of Luxembourg. Available from: http://www.sjes.ch/papers/2010-IV-2.pdf [Accessed: 15 January 2016].

79. Ibid.

80. McKenzie, D., and H. Rapoport (2010), "Self-Selection Patterns in MexicoU.S. Migration: The Role of Migration Networks," The Review of Economics and Statistics 92(4): 811-821. Available from: http://www.mitpressjournals.org/doi/ pdf/10.1162/REST_a_00032 [Accessed: 15 January 2016].

81. Bertoli, S., and H. Rapoport (2013), "Heaven's Swing Door: Endogenous Skills, Migration Networks and the Effectiveness of Quality-Selective Immigration Policies," IZA Discussion Papers 7749, Institute for the Study of Labor (IZA). Available from: http://ftp.iza.org/dp7749.pdf [Accessed: 15 January 2016].

82. Bertoli, S., V. Dequiedt, and Y. Zenou (2014), "Can Selective Immigration Policies Reduce Migrants' Quality?,' Working Paper halshs-01067461. Available from: http://halshs.archives-ouvertes.fr/docs/01/06/74/61/PDF/2014.19.pdf [Accessed: 15 January 2016].

83. Bertoli, S., and J. Fernández-Huertas Moraga (2012), "Visa Policies, Networks and the Cliff at the Border," IZA Discussion Papers 7094, Institute for the Study of 
Labor (IZA). Available from: http://ftp.iza.org/dp7094.pdf [Accessed: 15 January 2016].

84. Krassinets, E. (1998), "Illegal Migration and Employment in Russia," International Labour Organisation. Available from: http:/www.ilo.org/wcmsp5/groups/ public/---ed_protect/---protrav/---migrant/documents/publication/wcms_201973.pdf [Accessed: 15 January 2016].

85. See, e.g., Naumova, B. O. (2002), "The Kazakh Diaspora in Russia [Rossiia]," Anthropology \& Archeology of Eurasia 41(2): 23-42; Oussatcheva, M. (2009), "Institutions in Diaspora: The Case of Armenian Community in Russia," University of Oxford WPTC-01-09. Available from: http://www.transcomm.ox.ac.uk/working\% 20papers/WPTC-01-09\%20Marina.doc.pdf; Ryazantiev, S. (2014), "Chinese Migration and Chinese Diaspora in Russia," Migration Policy Centre Report 01. Available from: http://cadmus.eui.eu/bitstream/handle/1814/33141/MPC\%20RR $\% 202014 \%$ 20-\%2001.pdf?sequence=1 [Accessed: 15 January 2016].

86 Rossiyskaya Gazeta, "Federal Issue 5980 of 14 January 2013. Become a Citizen for 2 Million." Available from http://www.rg.ru/2013/01/14/immigraciya. html [Accessed: 15 January 2016].

87. According to the Constitution of the Russian Federation, federal entities are the top level political divisions of the country.

88. President of the Russian Federation, The President Approved the Concept of State Migration Policy of the Russian Federation for the Period up to 2025. Available from: http://kremlin.ru/news/15635 [Accessed: 15 January 2016].

89. The description of the United Kingdom's Migration Advisory Committee practices in this section draws closely on Marshall, R. (2011), "Value-Added Immigration. Lessons for the United States from Canada, Australia, and the United Kingdom," Economic Policy Institute. Available from: http://www.epi.org/publication/value-added-immigration [Accessed: 15 January 2016].

90. MAC identifies four categories of static shortages: "Cyclical shortages: these occur during periods of growth within a sector leading to an increase in the derived demand for skilled labor in related occupations. While we would expect to find a larger number of shortages during economic boom periods, cyclical shortages may be experienced during economic downturns if particular sectors perform better than the economy as a whole. The cyclical shortage occurs as a result of the imperfect responsiveness of labor supply to increases in labor demand. [...] Structural shortages: changes in the economy can lead to a demand for certain skills which are not readily available within the labor market, regardless of the level of unemployment. As a result, such shortages require focused skill development through education and training. [...] Public sector pay: public sector (or primarily publicly funded) occupations are particularly affected by budgetary restrictions which hinder employers' ability to increase the attractiveness of jobs by raising pay. [...] Global talent: in some cases only a relatively small number of people have the skills, knowledge, talent or ability to do the job in question and employers have limited options to address the deficit in the supply of skilled workers when compared to the demand for the skills in the occupation." Source: Skilled Shortage Sensible. Full review of the recommended shortage occupation lists for the UK and Scotland, a sunset clause and the creative occupations. Migration Advisory Committee. February 2013. Avail- 
able from: http://www.gov.uk/government/uploads/system/uploads/attachment_data /file/257241/mac-report.pdf [Accessed: 15 January 2016].

91. Ruhs, M. (2011), "Openness, Skills and Rights: An Empirical Analysis of Labour Immigration Programmes in 46 High- and Middle-income Countries."

92. Czaika, M., and H. De Haas (2013), "The Effectiveness of Immigration Policies."

93. See for more details De Haas, H. (2011), "The Determinants of International Migration: Conceptualizing Policy, Origin and Destination Effects," DEMIG project Paper 32. Available from: www.imi.ox.ac.uk/ pdfs/wp/wp-32-11.pdf [Accessed: 15 January 2016].

94. Emilsson, H. (2016), "Recruitment to Occupations with a Surplus of Workers: The Unexpected Outcomes of Swedish Demand-Driven Labour Migration Policy," International Migration 54(2): 5-17.

95. Emilsson, H., K. Magnusson, T. Osanami, and B. P. Sayaka (2014), "The World's Most Open Country: Labour Migration to Sweden after the 2008 Law," Malmö Institute for Studies of Migration, Diversity and Welfare (MIM), Malmö University, available from http://dspace.mah.se/dspace/bitstream/handle/2043/17818 /Current\%20Themes\%2015\%20muep.pdf;jsessionid=2EA6E163DA57828DAF613 D97FD51E2A4?sequence=2 [Accessed: 15 January 2016].

96. Czaika and De Haas (2013) are the authors of this point.

97. Decree No. 257 of 20 March 2015. Available from: http://government.ru/ media/files/TKJXPYGJRAU.pdf [Accessed: 15 January 2016]

98. Czaika, M., and H. De Haas (2013), "The Effectiveness of Immigration Policies."

99. Czaika, M., and H. de Haas (2011), "The Effectiveness of Immigration Policies. A Conceptual Review of Empirical Evidence," University of Oxford Working Paper No. 33. Available from: http://www.imi.ox. ac.uk/pdfs/wp/wp-33-11.pdf [Accessed: 15 January 2016].

100. The purpose of Appendix 1 is to illustrate the legacy of the Russian migration policy in the post-USSR period as a motivation for the introduction of the Concept of the State Migration Policy until 2025 (see Section 2 for a discussion). Therefore, for static structures and percentages, data from dates close to the introduction of the new migration concept have been used, and not the most recent available data. In contrast, graphics representing dynamics cover the migration reform period and recent data.

101. This disposition is activated in case of possession of a scientific degree as per article 6.2 of Federal Law No. 127-FZ of 23 August 1996 "On science and state science-technical policy."

102. Work experience considered in accordance with point 3 is excluded from consideration in points 4 and 5 .

103. Work experience considered in accordance with point 4 is excluded from consideration in points 3 and 5 .

104. Work experience considered in accordance with point 5 is excluded from consideration in points 3 and 4 .

105. The authorized capital of this legal entity must not be less than 50,000,000 RUB (approximately 730,072 USD as per the official RUB/USD exchange rate for 8 September 2015 of the Central Bank of Russia). The annual amount paid in taxes 
and fees in accordance with the legislation on taxes and fees (except for state fees and implemented refunds of wrongly paid and/or overpaid taxes and fees in accordance with the legislation on taxes and fees within the specified period) and insurance contributions into the pension fund of the Russian Federation must not be less than 6,000,000 RUB (approximately 87,609 USD as per the official RUB/ USD exchange rate for 8 September 2015 of the Central Bank of Russia).

106. The annual taxes and fees paid in accordance with the legislation on taxes and fees (except for property tax for physical persons, land tax, transport tax, state duties, and refunds of wrongly paid amounts and/or overpaid taxes and fees carried out in accordance with the legislation on taxes and fees) and insurance contributions into the pension fund of the Russian Federation must not be less than 500,000 RUB (approximately 7,301 USD as per the official RUB/USD exchange rate for 8 September 2015 of the Central Bank of Russia). 